\title{
Complicidad de las instituciones financieras internacionales en la violacion de derechos humanos en el contexto de reformas económicas
}

Complicity of international financial institutions in Human Rights violations in the context of economic reforms

\author{
Juan Pablo Bohoslavsky ${ }^{1}$
}

Revista Derechos en Acción ISSN 2525-1678/ e-ISSN 2525-1686

Año 6/No 18 Verano 2020-2021 (21 diciembre a 20 marzo), 216-274

DOI: https://doi.org/10.24215/25251678e482

Resumen: Este artículo demuestra que la introducción de medidas de ajuste no contribuye a la recuperación económica sino que, en cambio, trae aparejadas consecuencias negativas en términos de crecimiento económico, coeficientes de endeudamiento e igualdad, generando frecuentemente una serie de impactos negativos en materia de derechos

1 El autor fue Experto Independiente de las Naciones Unidas sobre deuda externa y derechos humanos, entre junio de 2014 y mayo de 2020.

El autor desea agradecer a Stephen Connelly, Nicolò Fraccaroli, Rafael Quintero Godínez y Celine Tan, por sus investigaciones y contribuciones al informe a la Asamblea General (A / 74/178, 16 de julio de 2019) en el que se basa este artículo y al personal de la Oficina del Alto Comisionado de las Naciones Unidas para los Derechos Humanos (OACNUDH) por el apoyo en la investigación. El autor también desea agradecer a Radhika Balakrishnan, Giuseppe Bianco, Danny Bradlow, Emma Burgisser, Meghan Campbell, Jernej Letnar Černič, Diane Desierto, Alexander Kentikelenis, Vladyslav Lanovoy, Kunibert Raffer, Margot Salomon e Ingo Venzke por sus opiniones, críticas y preguntas. La versión original de este artículo fue publicada en Columbia Human Rights Law Review (2020, Vol. 52:1), a quien se agradece la autorización para publicar esta versión en español. El autor también agradece a Juan Cruz Vallefín que tradujo este artículo al español. Las opiniones y conclusiones reflejadas en este artículo son únicamente las del autor y de ninguna manera tienen la intención de reflejar las opiniones de ninguna de las instituciones con las que el autor está afiliado. 
humanos. Y, por lo tanto, que existe una sólida base legal para sostener una inconsistencia prima facie entre la imposición de políticas de ajuste en tiempos de recesión y el disfrute de derechos humanos.

Debido a las circunstancias particulares en las que los Estados suelen encontrarse cuando requieren asistencia de instituciones financieras internacionales es que estas últimas suelen imponer condiciones que no necesariamente se han negociado con los Estados prestatarios. La población de los mismos se encuentra aún menos involucrada que su gobierno en las consultas, discusiones y negociaciones asociadas. El extenso alcance de tales condicionalidades, que se ha ampliado continuamente durante las últimas décadas, permite explicar su penetrante omnipresencia en cuestiones soberanas cruciales. Estas condicionalidades son observables aún en el contexto de la pandemia del COVID-19.

Según los estándares del derecho internacional, las instituciones financieras internacionales podrían ser consideradas responsables por la complicidad en la imposición de reformas económicas violatorias de derechos humanos. El nexo causal entre la asistencia brindada por las instituciones financieras internacionales (en forma de préstamos, vigilancia, asistencia técnica y condicionalidades anexas) en la comisión de un hecho internacionalmente ilícito (complicidad) y el daño causado (violaciones de derechos humanos) es evidente y se encuentra bien documentado. Se puede presumir que una institución tiene conocimiento de la naturaleza ilícita del acto si, incluso cuando se avanza en la implementación de reformas económicas que normalmente conducen a violaciones de derechos humanos, no se realiza una evaluación de impacto ex ante. La responsabilidad legal por complicidad genera obligaciones en términos de cesación, no repetición y reparación.

Abstract: This Article demonstrates that the introduction of austerity measures does not contribute to economic recovery, but instead has negative consequences in terms of economic growth, debt ratios, and equality, and routinely results in a series of negative human rights impacts. There is therefore a solid legal basis to make the case for a prima facie inconsistency between the imposition of austerity policies in times of recession and the enjoyment of human rights.

Because of the circumstances in which States usually find themselves when seeking assistance from international financial institutions, lender 
institutions often impose conditionalities that have not necessarily been negotiated with borrower States. States' populations are even less involved than their governments in the associated consultations, discussions, or negotiations. The broad scope of such conditionalities, which has been continuously expanded over recent decades, helps to explain their pervasiveness and omnipresence in key sovereign businesses. These conditionalities are even seen in the context of the COVID-19 pandemic.

According to standards of international law, international financial institutions may be held responsible for complicity in the imposition of economic reforms that violate human rights. The causal link between the assistance provided by international financial institutions (in the form of loans, surveillance and technical assistance, and attached conditionalities) in the commitment of an internationally wrongful act (complicity) and the harm done (human rights violations) is evident and well documented. An institution's knowledge of the wrongful nature of the act can be presumed if, even when advancing the implementation of economic reforms that normally lead to human rights violations, no ex ante impact assessment is undertaken. Legal responsibility for complicity raises obligations in terms of cessation, non-repetition, and reparation.

\section{Introducción}

En el 2017, respondiendo a la falta de guías bajo el derecho internacional en el campo de la evaluación del impacto de las reformas económicas sobre los derechos humanos, el Consejo de Derechos Humanos de la ONU le requitiró a este autor, como Experto Independiente de la misma entidad sobre Deuda Externa y Derechos Humanos, que desarrollara principios rectores sobre el tópico en cuestión. Como resultado de dos años de investigación y trabajo en colaboración, ${ }^{2}$ los Principios Rectores

2 Un número especial del International Journal of Human Rights está dedicado a estudiar las implicaciones de los Principios Rectores en una amplia gama de temas, incluida la recesión inducida por el COVID-19. Véase Aoife Nolan y Juan Pablo Bohoslavsky, "Human Rights and Economic Policy Reforms", 24 (9) International Journal of Human Rights, 2020, 1247, 1249-50. 
sobre la Evaluación del Impacto de las Reformas Económicas sobre los Derechos Humanos (desde ahora Principios Rectores) se presentaron al Consejo de Derechos Humanos y se votaron en $2019^{3}$.

Este artículo se construye a partir de estos Principios Rectores, centrándose más específicamente en la complicidad de las Instituciones Financieras Internacionales (IFI) al momento de la implementación por parte de los Estados de reformas económicas que violan los derechos económicos, sociales y culturales. ${ }^{4}$ Este artículo intenta responder a la siguiente pregunta: ¿se puede responsabilizar a las IFI por complicidad en la implementación por parte de los Estados de reformas económicas que violan los derechos humanos y, de ser así, bajo qué condiciones?

Además, brinda la oportunidad de considerar algunas implicaciones prácticas de los Principios Rectores 14 y 15, titulados, respectivamente, "Influencia externa y espacio de políticas" y "Obligaciones de los acreedores y donantes públicos". ${ }^{6}$ En el corazón de ambos principios se encuentra la obligación de los Estados y otros actores "de no ejercer una influencia externa indebida sobre otros Estados para que puedan diseñar y ejecutar programas económicos utilizando su espacio de políticas de acuerdo con sus obligaciones de derechos humanos, incluso cuando se trata de hacer frente a crisis económicas o

3 Informe del Experto en Deuda y Derechos Humanos, “Guiding Principles on Human Rights Impact Assessments of Economic Reforms", U.N. Doc. A/HRC/40/57 (19 de diciembre de 2018) [Principios Rectores], aprobado por el Consejo de Derechos Humanos, Res. 40/8, U.N. Doc. A/HRC/RES/40/08 (21 de marzo de 2019).

4 Las Instituciones Financieras Internacionales (IFI) incluyen, sobre todo, el Fondo Monetario Internacional (FMI) y el Banco Mundial (Grupo del Banco Mundial o GBM). Para conocer los orígenes y las ideas políticas detrás de las instituciones de Bretton Woods, véase en general Benn Steil, The Battle of Bretton Woods: John Maynard Keynes, Harry Dexter White and the Making of a New World Order (Princeton University Press, 2013) (que describe el proceso que condujo a la establecimiento de reglas internacionales para la gestión monetaria y las IFI originales).

5 Principios Rectores, supra nota 3, princ. 14

6 Id. Princ. 15. 
financieras". 7 Además, el Principio Rector 15 específicamente instruye a las IFI, los prestamistas bilaterales y los donantes públicos a "garantizar que los términos de sus transacciones y sus propuestas de políticas de reformas y las condiciones para el apoyo financiero no socaven la capacidad del Estado prestatario/ receptor de respetar, proteger y cumplir con sus obligaciones de derechos humanos". 8

De conformidad con los Principios Rectores, la realización de evaluaciones de impacto sobre los derechos humanos en el diseño de programas de reforma económica por parte de las IFI es fundamental. ${ }^{9}$ La consideración sistemática de los impactos de tales programas en los derechos humanos tiene como objetivo garantizar que los daños se prevengan, compensen y no se repitan. Estas evaluaciones deben realizarse en armonía con las salvaguardas y mecanismos existentes para contribuir a la toma de decisiones informada y complementar los hallazgos desde una perspectiva de derechos humanos. ${ }^{10}$

La facilitación de un hecho internacionalmente ilícito por parte de un prestamista puede violar los derechos civiles y políticos, así como los derechos económicos, sociales y culturales. ${ }^{11}$ Por ejemplo, en un estudio temático sobre complicidad

7 Id. Princ. 14.

8 Id. Princ. 15

9 Id. Princ. 7; ver también Off. of the U.N. High Comm'r for Hum. Rts., U.N. Dev. Programme \& U.N. Sustainable Dev. Grp, "Checklist for a Human Rights-Based Approach to Socio-Economic Country Responses to COVID-19" 17 (Julio 2020) (recomendando que se lleven a cabo evaluaciones de impacto sobre los derechos humanos antes de instituir políticas de reforma fiscal y económica) [U.N. Checklist for Human Rights and COVID-19]; "The OPERA Framework", Center for Economic and Social Rights, https://www.cesr.org/opera-framework [https://perma.cc/ M42K-D4KD] (presenta "un marco de cuatro pasos simple pero completo para analizar varios aspectos de la obligación de cumplir con los derechos económicos y sociales").

10 Id. Princ. 8-9.

11 Los derechos civiles y políticos — como el derecho a la vida, al debido proceso, y a la libertad de expresión - económicos, sociales y culturales — como el acceso al agua, a la vivienda y educación - están protegidos a nivel internacional. La división básica entre ambos conjuntos de derechos se estableció con la adopción por la Asamblea General de las 
financiera presentado al Consejo de Derechos Humanos en 2014, este autor concluyó que otorgar préstamos a los Estados que cometen graves violaciones de derechos humanos puede contribuir a la consolidación del régimen y aumentar la probabilidad de que se produzcan nuevas violaciones graves de derechos. ${ }^{12}$ En 2018, el autor reiteró este argumento en un amicus curiae presentado en relación con el supuesto incumplimiento de dos bancos de las directrices promulgadas por la Organización para la Cooperación y el Desarrollo Económico (OCDE) sobre el embargo de armas de la ONU contra el régimen del apartheid en Sudáfrica. ${ }^{13}$ La denuncia fue examinada por los puntos de contacto nacionales de Bélgica y Luxemburgo ${ }^{14}$ de conformidad con las Directrices de la OCDE para empresas multinacionales. ${ }^{15}$

Naciones Unidas en 1966 del Pacto Internacional de Derechos Civiles y Políticos (PIDCYP) y el Pacto Internacional de Derechos Económicos, Sociales y Culturales (PIDESC), los cuales entraron en vigor en 1976. OHCHR, The UN Human Rights Treaty System, 6-7 (2012). Hoy en día, los derechos están protegidos a nivel internacional por una red de tratados y pactos, así como por un cuerpo de derecho consuetudinario en constante expansión. Id. 4, 18.

12 Informe del Experto en Deuda y Derechos Humanos, "Responsilibity for Financial Complicity: Lending to States Engaged in Gross Human Rights Violations", U.N. Doc. A/HRC/28/59 (22 de diciembre de 2014).

13 "Submission: Complaint Brought to the OECD by Open Secrets and the Centre for Applied Legal Studies Concerning the Conduct of KBL European Private Bankers and KBC Group Belgium", U.N. Hum. Rts. Special Proc. (may. 28, 2018). El Consejo de Seguridad de la ONU impuso un embargo de armas obligatorio contra Sudáfrica en 1977 en condena del violento y racista régimen del apartheid. S.C. Res. 418 (nov. 4, 1977) Este embargo se amplió posteriormente a lo largo de la década de 1980. Ver S.C. Res. 558 (dic. 13, 1984) (solicitando a los Estados que se abstengan de importar equipo militar de fabricación sudafricana); S.C. Res. 591 (nov. 28, 1986) (endurecimiento y ampliación del embargo de armas).

14 "Apartheid and Bank Complicity Case: UN Expert Urges Reform of OECD Review Mechanism to Protect Human Rights", Off. U.N. High Comm'r for Hum. Rts. (abr. 27, 2020), https:// www.ohchr.org/EN/NewsEvents/Pages/DisplayNews.aspx?News|D=25831\&amp;LangID=E [https://perma.cc/DXM8-97CS]. Las denuncias fueron desestimadas en una etapa preliminar sin una consideración completa de las pruebas y el amicus curiae presentado. Al parecer, hubo un grave conflicto de intereses en el sentido de que uno de los representantes del comité del punto de contacto nacional del sector privado, quien tomó la decisión, también fue uno de los prestamistas denunciados. Id.

15 Org. for Econ. Coop. \& Dev., "OECD Guidelines for Multinational Enterprises" (OECD Publishing 2011). 
Sin embargo, los debates políticos y académicos han prestado mucha menos atención ${ }^{16}$ a si los prestamistas pueden ser considerados cómplices del financiamiento y promoción de políticas o medidas que violan los derechos económicos, sociales y culturales. ${ }^{17}$ Una excepción a esta tendencia es una visión emergente que afirma firmemente que ciertas violaciones de los derechos económicos, sociales y culturales pueden considerarse crímenes internacionales. ${ }^{18}$ Sin embargo, aquello que puede considerarse un delito socioeconómico internacional es obviamente bastante limitado y no da cuenta plenamente de las violaciones de los derechos económicos, sociales y culturales, relacionadas con medidas económicas regresivas inadmisibles. ${ }^{19}$

16 Ver Sabine Michalowski, Introduction to Corporate Accountability in the Context of Transitional Justice, 1 (Sabine Michalowski ed., Routledge 2013) (señalando que la literatura que analiza "Ios vínculos entre la responsabilidad empresarial y la justicia transicional" es "casi inexistente").

17 Ver e.g., Antonio Cassese (Special Rapporteur), Study of the Impact of Foreign Economic Aid and Assistance on Respect for Human Rights in Chile, U.N. Doc E/CN.4/Sub.2/412 (Vols. I-IV) (20 de julio de 1978) (considerando, en un informe de cuatro volúmenes, las consecuencias adversas para los derechos humanos de la ayuda económica y la asistencia brindada al gobierno chileno, pero centrándose exclusivamente en las violaciones de los derechos civiles y políticos); Robert Howse, The International Criminal Court Should Investigate Germany's Finance Minister for Crimes Against Humanity in Greece, Int'I Econ. L. \& Pol'y Blog (15 de diciembre de 2016), https:// worldtradelaw.typepad.com/ielpblog/2016/12/the-international-criminal-court-should-investigate-germanys-finance-minister-for-crimes-against-hum.html [https://perma.cc/5VC7-Z5WH] (sugiriendo que el ministro de finanzas de Alemania podría ser considerado responsable de causar "gran sufrimiento" al imponer medidas punitivas de austeridad en Grecia, y recomendando una investigación sobre los efectos de esas medidas en parte porque "Ios defensores de los derechos humanos, especialmente los que se ocupan de los derechos sociales y económicos, tienen un gran interés en un caso que lo ilustra... Las graves violaciones de derechos humanos ocurren en contextos distintos al conflicto armado o la opresión del Estado policial.").

18 Ver Evelyne Schmid, Taking Economic, Social and Cultural Rights Seriously in International Criminal Law, (Cambridge University Press, 2015) (Proporciona evidencia legal y jurisprudencial para argumentar que las violaciones de los derechos económicos, sociales y culturales pueden constituir crímenes internacionales: por ejemplo, cortar el acceso al suministro de agua en el contexto de un conflicto). Sobre la posibilidad de comisión de crímenes internacionales en el manejo gubernamental de la pandemia del COVID-19 en Brasil, ver la entrevista a Deisy Ventura, en Eliane Brum, "Hay indicios significativos para que autoridades brasileñas, incluido Bolsonaro, sean investigadas por genocidio", El País, 25 de julio de 2020.

19 La situación tendría que constituir simultáneamente una violación de un derecho económico o social y un crimen internacional en virtud del Estatuto de Roma de la Corte Penal 
Si bien las medidas de ajuste - que incluyen la consolidación fiscal, las reformas de ajuste estructural, privatización, desregulación de los mercados financieros y laborales, y la debilitamiento de las normas de protección ambiental-, pueden ser adoptadas por los Estados por iniciativa propia, suelen figurar en las condiciones prescritas incluidas en los acuerdos entre Estados e IFI. ${ }^{20}$ La responsabilidad de los Estados por la violación de los derechos económicos, sociales y culturales mediante la imposición de tales medidas puede establecerse de manera directa, pero las IFI también pueden contribuir a las violaciones de esos derechos en el contexto de sus préstamos, vigilancia y operaciones de asistencia técnica. ${ }^{21} \mathrm{Al}$ prescribir reformas económicas con previsibles efectos negativos sobre los derechos humanos, las IFI pueden ser consideradas responsables por complicidad.

Aunque el término complicidad generalmente se refiere al derecho penal, ${ }^{22}$ este artículo explora el concepto desde una perspectiva general del derecho internacional. La noción de responsabilidad debe entenderse desde un punto de vista similar. En este contexto, la responsabilidad por complicidad debe verse como un tipo de responsabilidad compartida. ${ }^{23}$ De acuerdo con el derecho internacional, la responsabilidad por complicidad

\footnotetext{
Internacional. Ver id. en 22-26 (argumentando que el derecho penal internacional, tal como se define en los artículos del Estatuto de Roma que establecen la jurisdicción de la Corte Penal Internacional, cubre las violaciones de los derechos económicos, sociales y culturales).

20 Ver infra sección I.B (la cual describe la prevalencia de medidas de ajuste basadas en los acuerdos entre Estados e IFI).

21 Ver infra Sección III.A (la cual describe la complicidad de las IFI en la violación de los derechos económicos, sociales y culturales generadas a partir de acuerdos)

22 El derecho penal tiende a tomar en cuenta la complicidad al establecer responsabilidad por ayudar e incitar a otra persona a cometer un delito. Ver e.g., Cong. Rsch. Serv., R43770, Accomplices, Aiding and Abetting, and the Like: An Abbreviated Overview of 18 U.S.C. § 2, summ. (2020) (estableciendo que bajo el derecho de Estados Unidos, ayudar o facilitar significa asistir en la comisión de un crimen ejecutado por otra persona).

23 Vladyslav Lanovoy, Complicity and its Limits in the Law of International Responsibility 11 (2016).
} 
requiere: (a) la comisión de un acto considerado ilícito según el derecho internacional; (b) conocimiento por parte del Estado o del facilitador (como una organización internacional) de un elemento de ilicitud, que incluye una ceguera intencional; y (c) un nexo causal -facilitación- entre los bienes o servicios provistos por el facilitador y el daño causado - en este caso por la violación de los derechos humanos debido a una política económica implementada por un determinado Estado- $-{ }^{24}$

Cuando una IFI incluye condicionalidades de asistencia técnica, vigilancia y préstamos sin considerar si los términos impuestos podrían ser perjudiciales para los derechos económicos, sociales y culturales, surgen serias preocupaciones. ${ }^{25}$ Cuando ocurren violaciones de derechos humanos como resultado de la implementación de tales condicionalidades, es importante determinar la responsabilidad de los involucrados, de modo que tanto los perpetradores directos o principales - los Estadoscomo sus cómplices - las IFI- puedan rendir cuentas.

La responsabilidad de las IFI por su complicidad en las violaciones de derechos humanos resultantes de las reformas económicas constituye un problema jurídico urgente. A pesar del amplio acuerdo sobre la necesidad de fortalecer el espacio fiscal de los Estados para hacer frente a la crisis de COVID-19, ${ }^{26}$ el 23 de marzo de 2020, durante el pico inicial del brote de la pandemia, el presidente del Banco Mundial explicó que si bien los países necesitan para "impulsar el gasto en salud, fortalecer las redes de

24 G.A. Res. 66/100, art. 14, Responsibility of International Organizations (9 de diciembre de 2011).

25 Ver Margot E. Salomon, "Of Austerity, Human Rights and International Institutions", 21 Eur. L.J. 521, 525-27 (2015) (describiendo cómo la imposición de medidas de austeridad en países con economías en problemas puede conducir a una abdicación de la responsabilidad del Estado por los derechos sociales y humanos, dando como resultado, entre otros efectos, un debilitamiento de los sindicatos y las instituciones de política social, lo que significa que los efectos nocivos de austeridad se distribuyen de manera desigual).

26 Ver, e.g., ONU, "UN Framework for the immediate socio-economic response to COVID-19" (2020) (identificando un "aumento necesario en el estímulo fiscal y financiero" al comienzo de la crisis de COVID-19). 
seguridad social, apoyar al sector privado y contrarrestar la disrupción del mercado financiero", también "necesitarán implementar reformas estructurales para ayudar a acortar el tiempo de recuperación y generar confianza en que la recuperación puede ser sólida". ${ }^{27}$ Además, pareciera que las nuevas modalidades de adquisiciones rápidas a través de las cuales el Banco Mundial planea comprar suministros médicos al por mayor financiarían servicios de salud privados que podrían requerir personal muy necesario de los sistemas de salud pública. ${ }^{28}$

Del mismo modo, mientras reconoció la urgente necesidad de aumentar el gasto social para proteger a las personas más expuestas a las consecuencias económicas de la pandemia, el FMI destacó en abril de 2020 que "una vez superada la crisis del COVID-19, las políticas fiscales prudentes exigen ajustes a un ritmo adecuado, inclusivos y creíbles, para poner los índices de deuda en una firme trayectoria descendente". 29 En otras palabras, el FMI considera que tan pronto como haya pasado la crisis económica precipitada por COVID-19, "se necesita un camino de consolidación fiscal a mediano plazo más ambicioso y creíble para reducir el gasto en deuda e intereses". ${ }^{30}$

Estas declaraciones indican que el Banco Mundial y el FMI no tienen ninguna intención de abandonar su agenda de austeridad y ortodoxia a pesar de una crisis global que, como

27 David Malpass, President, World Bank Grp., “Remarks by World Bank Group President David Malpass on G20 Finance Ministers Conference Call on COVID-19" (23 de marzo de 2020), https://www.worldbank.org/en/news/speech/2020/03/23/remarks-by-world-bankgroup-president-david-malpass-on-g20-finance-ministers-conference-call-on-covid-19 [https://perma.cc/QD2U-WMKH].

28 Alexander Kentikelenis et al., "Softening the Blow of the Pandemic: Will the International Monetary Fund and World Bank Make Things Worse?", 8(6) Lancet Glob. Health e758, e758-59 (2020), https://www.thelancet.com/action/showPdf?pii=S2214-109X \%2820 \%2930135-2 [https://perma.cc/96KH-4XS7].

29 FMI, "Policies to Support People During the COVID-19 Pandemic", Fiscal Monitor 20 (abril de 2020).

$30 \mathrm{Id}$. 
reconocen, ha aumentado drásticamente la necesidad de gasto público en salud y servicios sociales en casi todos los países del mundo. ${ }^{31}$ Subrayando esta intención está el hecho de que, a julio de 2020, Ecuador todavía estaba experimentando reformas estructurales ordenadas por el FMI. ${ }^{32}$ Además, su último acuerdo de préstamo incluye estrictos compromisos de consolidación fiscal $^{33}$ que corren el riesgo de desmantelar aún más el sistema de salud ecuatoriano.

Este artículo comenzará explorando la noción de condicionalidad, los procesos de formulación de políticas y las principales áreas de prescripción. Al centrarse en las reformas económicas y la austeridad como base para muchas condicionalidades, la Parte I explicará sus efectos sobre el crecimiento, la sostenibilidad de la deuda y la igualdad. La Parte II luego deconstruirá las teorías económicas que apoyan la austeridad. La Parte III describirá el impacto de las reformas económicas en el disfrute de los derechos humanos. Estos hallazgos y argumentos prepararán el escenario para la Parte IV, que examinará el concepto de responsabilidad legal por complicidad e investigará su aplicabilidad a las IFI que apoyan políticas que previsiblemente

31 Malpass, supra nota 27; IMF, supra nota 29, at 20; Press Release, Oxfam Int'I, "IMF Paves Way for New Era of Austerity Post-COVID-19", (12 de octubre de 2020), https://www.oxfam. org/en/press-releases/imf-paves-way-new-era-austerity-post-covid-19 [https://perma.cc/ A6T6-JYFG]; Daniel Munevar, Eur. Network on Debt \& Dev., "Arrested Development: IMF Lending and Austerity Post Covid-19", (oct. 2020); "Over 500 Organisations Call on IMF to Stop Promoting Austerity in Coronavirus Recovery Period", Pub. Servs. Int'I (6 de octubre de 2020), https://publicservices.international/resources/news/over-500-organisations-call-onimf-to-stop-promoting-austerity-in-coronavirus-recovery-period?id=11190\&lang=en [https:// perma.cc/8K3C-A448].

32 FMI, Ecuador: Request for Purchase Under the Rapid Financing Instrument and Cancellation of Arrangement Under the Extended Fund Facility-Press Release; Staff Report; and Statement by the Executive Director for Ecuador, Country Report No. 20/178, 50 (mayo de 2020).

33 Id. at 15-17; ver también Comm. on Econ., Soc. \& Cultural Rts., Concluding observations on the fourth periodic report of Ecuador, 5, 7, 8, 68, U.N. Doc. E/C.12/ECU/CO/4 (14 de noviembre de 2019) (expresando preocupación por el impacto de las medidas de austeridad impuestas por el FMI, así como por la respuesta de Ecuador a las protestas que estallaron por los términos de esas medidas, y recomendando que Ecuador mejore la consulta comunitaria al adoptar una nueva política económica). 
conduzcan a la violación de los derechos humanos. La última parte de este artículo presentará conclusiones y recomendaciones destinadas a fomentar la discusión.

\section{Condiciones promovidas por las instituciones financieras internacionales: procesos débiles y alcances en expansión}

En general, cuando un país pide prestado a una IFI, su gobierno debe acordar ajustar sus políticas económicas para superar los problemas que, en opinión de las IFI, lo llevaron a buscar ayuda financiera de la comunidad internacional. ${ }^{34} \mathrm{La}$ inclusión de tales condiciones tiene por objeto garantizar que el país pueda reembolsar el préstamo. ${ }^{35}$

Para las IFI, las condicionalidades son elementos clave de los acuerdos de financiación. Como explica el FMI: "Normalmente, el gobierno de un país y el FMI deben acordar un programa de políticas económicas antes de que el FMI otorgue préstamos al país. Los compromisos de un país de emprender determinadas acciones de política, conocidas como condicionalidad de política, son en la mayoría de los casos una parte integral de los préstamos del FMI". ${ }^{36}$ Como resultado, los recursos solo pueden ser liberados por el FMI "[una] vez que se haya llegado a un entendimiento sobre las políticas y un paquete de financiamiento...". ${ }^{37}$ Sin embargo, las evaluaciones de impacto sobre los derechos humanos, un esfuerzo serio para prever las consecuencias de los préstamos y las condicionalidades en los derechos humanos, ${ }^{38}$ no se están llevando a cabo de manera sistemática o incluso ocasionalmente antes de la celebración

\footnotetext{
34 IMF, IMF Conditionality, Fact Sheet (30 de marzo de 2020), https://www.imf.org/en/About/ Factsheets/Sheets/2016/08/02/21/28/IMF-Conditionality [https://perma.cc/U76B-DVGC].

$35 \mathrm{Id}$.

36 FMI, IMF Lending, Fact Sheet (27 de marzo de 2020), https://www.imf.org/en/About/ Factsheets/IMF-Lending [https://perma.cc/3C4E-YCBC] (citation omitted).

$37 \mathrm{Id}$.

38 Principios Rectores, supra nota 3, princ. 17-18
} 
de acuerdos de financiamiento o la adopción de reformas para garantizar que los acuerdos y condicionalidades cumplen con las normas internacionales de derechos humanos. ${ }^{39}$

El componente de la Asociación Internacional de Fomento del Banco Mundial se especializa en créditos, que pueden describirse como préstamos sin intereses, mientras que su Banco Internacional de Reconstrucción y Fomento otorga préstamos a "países de ingresos medios y bajos solventes". ${ }^{40}$ Como otros bancos de desarrollo, estas subsidiarias del Banco Mundial imponen condiciones a los préstamos que otorgan a los Estados miembros. ${ }^{41}$ El Banco también proporciona financiamiento de proyectos para varios proyectos discretos, que a menudo conllevan su propia gama de condiciones. ${ }^{42}$ Este artículo, sin embargo, se centra en las operaciones de préstamos para políticas de las IFI, que a menudo imponen condicionalidades macroeconómicas. ${ }^{43}$ También se incluyen condiciones similares en los acuerdos de la Comisión Europea y el Banco Central Europeo, ${ }^{44}$ incluso como parte de los programas de ajuste económico, que de hecho se asemejan a los muy criticados programas de ajuste estructural implementados en el pasado. ${ }^{45}$

Las siguientes secciones presentarán y discutirán los aspectos procedimentales y sustantivos de las condicionalidades de

39 Nolan y Bohoslavsky, supra nota 2.

40 WBG, About the World Bank, http://www.worldbank.org/en/about [https://perma.cc/ ZAM8-QDXV].

$41 \mathrm{Id}$.

42 Ver Action Aid Int'l, "What Progress? A Shadow Review of World Bank Conditionality" (2006) (discutiendo el financiamiento de proyectos en el contexto del incumplimiento de la condicionalidad de ciertos principios básicos como la transparencia, la apropiación local y la personalización).

43 Ver infra Sección I.B. (que describe las condicionalidades macroeconómicas incluidas en los acuerdos del FMI).

44 Experto Independiente en Deuda y Derechos Humanos, "Report on Mission to Greece", 5 , 19-20, U.N. Doc. A/HRC/31/60/Add.2 (21 de abril de 2016).

45 Scott Greer, "Structural Adjustment Comes to Europe: Lessons for the Eurozone from the Conditionality Debates", 14(1) Glob. Soc. Pol'y, 54-60 (2013). 
las IFI. La Sección I.A. discutirá las asimetrías de poder inherentes a los procesos mediante los cuales las IFI llegan a acuerdos de préstamo mientras que la Sección I.B. explorará el contenido de las condicionalidades incluidas en dichos acuerdos.

\section{A. Procedimientos problemáticos}

Observar los procesos de formulación de políticas de las IFI ayuda a comprender sus resultados. El proceso que rodea a la celebración de un acuerdo con el FMI, por ejemplo, incluye varios pasos: en general, el personal del FMI y las y los representantes del gobierno solicitante participan primero en una serie de reuniones destinadas a evaluar la situación económica y financiera específica del país. ${ }^{46}$ Normalmente se llega a un acuerdo y el gobierno prepara una carta de intención, a la luz de la variedad de condiciones establecidas, que va acompañada de un memorando de entendimiento que proporciona más detalles sobre los compromisos del gobierno con el Fondo. ${ }^{47}$

Agravadas por la urgencia o la gravedad de situaciones específicas de un país, ${ }^{48}$ las circunstancias que rodean la celebración de acuerdos a menudo reflejan una cierta dinámica asimétrica. Los debates se llevan a cabo principalmente a nivel de expertos/as: los/as representantes del gobierno prestatario

46 Giuseppe Bianco \& Filippo Fontanelli, “Enhancing the International Monetary Fund's Compliance with Human Rights: The Issue of Accountability", en Making Sovereign Financing and Human Rights Work 213, 227-28 (Juan Pablo Bohoslavsky \& Jernej Letnar Černič eds., 2014).

47 Id.

48 Argentina y Grecia son casos convincentes. Ver Alfredo Fernando Calcagno, "Managing Public Debt Crisis in Argentina: Between Sovereignty and Subordination", in Sovereign Debt Crises: What Have We Learned?, 12 (Juan Pablo Bohoslavsy \& Kunibert Raffer eds., 2017) (que describe los desafíos de Argentina para administrar su deuda soberana); Kunibert Raffer, Greece: an EU-Inflicted Catastrophe, in Juan Pablo Bohoslavsy \& Kunibert Raffer cit. (que describe los desafíos de Grecia por gestionar su deuda soberana). Las experiencias de Argentina y Grecia muestran que los países que necesitan urgentemente asistencia financiera tienen una capacidad muy limitada para negociar los términos de esa asistencia. Ver también Menéndez, infra nota 66 y texto adjunto (que expone la falta de discusión pública sobre el contrato de préstamo de Argentina). 
normalmente negocian el programa nacional directamente con el personal del FMI antes de presentarlo al Directorio Ejecutivo del FMI. ${ }^{49}$ Normalmente no hay participación de parlamentarios/as, cámaras corporativas, sindicatos u organizaciones de la sociedad civil, a pesar de que los préstamos y las condicionalidades adjuntas a los acuerdos afectarán regularmente a todas estas partes interesadas. ${ }^{50}$

En cuanto al calendario, lo que a veces se denomina "medidas previas" ${ }^{51}$ y que son en la práctica condiciones previas que se espera que cumplan los Estados prestatarios para ser elegibles para un préstamo, son ahora a menudo un aspecto esencial del proceso de préstamo. ${ }^{52} \mathrm{Si}$ bien no son vinculantes en sí mismas, estas condiciones previas desempeñan un papel importante en las políticas nacionales. ${ }^{53}$ En opinión de muchas IFI, las condiciones previas permiten una mayor "propiedad" de las reformas que se implementan. ${ }^{54} \mathrm{Al}$ igual que otras formas de condicionalidad, no se consideran obligaciones contractuales, sino más bien requisitos políticos o financieros que deben implementarse de forma voluntaria. ${ }^{55}$ El objetivo de las acciones previas es recompensar el "buen comportamiento" de los Estados en la implementación de esos requisitos. ${ }^{56}$

\footnotetext{
49 Bianco \& Fontanelli, supra nota 46.

$50 \mathrm{Id}$.

51 IMF Conditionality, supra nota 34.

52 Celine Tan, Governance Through Development: Poverty Reduction Strategies, International Law and the Disciplining of Third World States, 119-21 (2011).

53 Id.

54 Stanley Fischer, First Deputy Managing Dir., IMF, Priorities for the IMF, Remarks to the Bretton Woods Committee (27 de abril de 2001), https://www.imf.org/en/News/ Articles/2015/09/28/04/53/sp042701 [https://perma.cc/E5LM-VFGD] (afirmando que "la condicionalidad excesiva [a diferencia de la precondicionalidad menos formal] socava el sentido de propiedad de esas políticas... porque se considera que las políticas se imponen desde fuera").

55 Tan supra nota 52, 119.

56 Id. 119-21 (2011).
} 
Cuando está listo para ser presentado, los veinticuatro directores del Directorio Ejecutivo del FMI deciden sobre el acuerdo, generalmente por consenso $\mathrm{y}$, a veces, mediante un proceso de votación. ${ }^{57}$ Si bien es poco común, se puede presentar un plan a la Junta Ejecutiva para que los/as representantes de los países que forman parte de la Junta puedan revisar los componentes de un programa que podrían poner en riesgo el disfrute de los derechos humanos, de conformidad con sus obligaciones en virtud del derecho internacional. ${ }^{58}$ Sin embargo, la falta de aportes de una serie de partes interesadas no solo impide que los Estados tengan información de primera mano sobre el nivel de aceptación o "propiedad" del acuerdo por parte del país, sino que el proceso de toma de decisiones tampoco permite fácilmente plantear cualquier posible oposición a los programas. ${ }^{59}$

Además, parece que cuanto más necesita un préstamo un Estado, menos poder de negociación y espacio de negociación tiene. ${ }^{60} \mathrm{Si}$ bien es cierto que el proceso que lleva a la conclusión de tales acuerdos ofrece alguna base para una discusión

57 FMI. "How the IMF Makes Decisions", Fact Sheet (mar. 8, 2019), https://www.imf.org/en/ About/Factsheets/Sheets/2016/07/27/15/24/How-the-IMF-Makes-Decisions [https://perma. cc/AY75-XTDD].

58 De esta manera, los deberes de los Estados partes del PIDESC tienen un "efecto indirecto" sobre el FMI. François Gianviti, Economic, Social and Cultural Rights and the International Monetary Fund, 3 Current Devs. in Monetary \& Fin. L. 3, 13 (2005); Comm. on Econ., Soc., \& Cultural Rts., Public Debt, Austerity Measures and the International Covenant on Economic, Social, and Cultural Rights, 9, U.N. Doc. E/C.12/2016/1 (julio 22, 2016) [Public Debt, Austerity Measures, \& ICESCR] (aclarando "que los Estados Partes en el Pacto tienen obligaciones como Estados miembros de instituciones financieras internacionales, en general, y del FMI, en particular").

59 Ver Yilmaz Akyuz, Reforming the IMF: Back to the Drawing Board, 20 (2005) (señalando el dominio de unas pocas naciones en el Directorio del FMI y afirmando la necesidad de "eliminar el poder de veto de los principales accionistas del Fondo sobre decisiones clave" y reasignar los derechos de voto "para aumentar la voz de los países en desarrollo").

60 Tan, supra nota 52, 120; 1 Paul Mosley et al., Aid and Power: The World Bank and PolicyBased Lending 130-31 (2da ed. 1995) (proponiendo que “[e]l costo de no hacer ningún trato será más serio para el receptor... cuanto más grave sea su situación económica y menor sea su capacidad para obtener financiamiento para el desarrollo de otras fuentes"). 
bidireccional, la naturaleza misma del documento legal está más cerca de un contrato de adhesión que del resultado de un encuentro de voluntades a través de un acuerdo bilateral plenamente negociado. Los/as académicos/as han destacado que según las directrices del FMI sobre condicionalidades, los arreglos no se consideran "acuerdos" y se evita el lenguaje contractual, lo que demostraría el carácter unilateral de las decisiones del Directorio del FMI. ${ }^{61}$ Finalmente, la relación asimétrica entre los Estados prestatarios y el FMI se ve acentuada por el hecho de que el FMI es efectivamente un prestamista de última instancia dada la ausencia de un mecanismo global alternativo para responder a las crisis de deuda. ${ }^{62}$

Cuando se está considerando el impacto social de tales reformas, la consulta y la participación de la población afectada en los procesos de negociación es bastante limitada, a menudo equivale a un mero ejercicio de "marcar casillas". ${ }^{63}$ Tampoco se reflejan las opiniones de la población en el contenido de las condicionalidades. ${ }^{64}$ En este sentido, en un informe de misión a la Unión Europea, el autor subrayó la importancia de respetar determinadas obligaciones cuando se negocian y diseñan políticas económicas, incluso en términos de transparencia, participación y rendición de cuentas. ${ }^{65}$ Esto presenta un desafío importante, ya que con demasiada frecuencia los gobiernos pueden querer limitar la transparencia y la participación pública en tales discusiones y negociaciones. ${ }^{66}$

\footnotetext{
61 Bianco \& Fontanelli, supra nota 47, 228.

62 Catherine Schenk, The IMF Remains the Lender of Last Resort-Literally, Chatham House, https://www.chathamhouse.org/2018/06/imf-remains-lender-last-resort-literally [https:// perma.cc/JXB4-CN8C].

63 Experto Independiente en Deuda y Derechos Humanos, "Mission to Institutions of the European Union", 69-70, U.N. Doc. A/HRC/34/57/Add.1 (28 de diciembre de 2016).

$64 \mathrm{Id}$.

$65 \mathrm{Id}$.

66 Al recurrir al FMI, los gobiernos suelen encontrarse en una posición económica y política débil y, por lo tanto, pueden estar abiertos a considerar condiciones inconvenientes para sus
} 


\section{B. Número y alcance de las condicionalidades}

Las condicionalidades reducen considerablemente el espacio legal y de formulación de políticas nacionales, mientras que exclusiva (y teóricamente) tienen como objetivo hacer que la deuda sea sostenible, mejorar la competitividad del mercado e impulsar el crecimiento inclusivo a través de políticas como la reducción de los estándares de protección de la legislación laboral. ${ }^{67} \mathrm{El}$ sistema de condicionalidades del FMI evolucionó a lo largo de décadas y, a pesar de un discurso que enfatiza su transformación fundamental, estudios recientes sugieren que los cambios han sido bastante limitados. ${ }^{68}$ La austeridad y otras políticas económicas ortodoxas conforman los fundamentos teóricos de la mayoría de las condicionalidades macroeconómicas, incluso en el contexto del COVID-19. ${ }^{69}$

Si bien el FMI ha reconocido en el pasado el papel clave de las medidas de política anticíclicas y ha afirmado preservar

países cuando aceptar las condiciones podría proporcionarles ventajas políticas a corto plazo. Por ejemplo, un acuerdo firmado por Argentina y el FMI en 2019 no siguió a ninguna discusión pública, lo que dio lugar a un caso legal basado en el argumento de que el acuerdo no fue precedido por ningún informe técnico de las autoridades nacionales pertinentes, como la del Banco Central. V. Carmen Menéndez, “Denuncian al Presidente Argentino, Mauricio Macri, por el Acuerdo de Préstamo con el FMI", Euronews (4 de diciembre de 2019), https://es.euronews.com/2019/ 12/04/denuncian-al-presidente-argentino-mauricio-macri-por-el-acuerdo-de-prestamo-conel-fmi [https://perma.cc/907K-NTDH].

67 Thomas Stubbs \& Alexander E. Kentikelenis, "Conditionality and Sovereign Debt: An Overview of Human Rights Implications", en Debt and Human Rights 359, 359, 374-77 (Ilias Bantekas \& Cephas Lumina eds., 2018); Peter Bakvis, Orthodoxy, Evidence and Action: Labour Rights at the World Bank, 24 Int'I Union Rts. 3, 3 (abr. 2017) (destacando la resistencia del Banco Mundial y del FMI a abandonar su "creencia de que los mercados laborales no regulados son un ingrediente necesario" en el crecimiento económico, a pesar de la abundante evidencia en contrario).

68 Ver Alexander E. Kentikelenis et al., "IMF Conditionality and Development Policy Space, 1985-2014", 23 Rev. Int'I Pol. Econ. 543, 543 (2016) (que examina el uso de la condicionalidad de las políticas en los acuerdos de préstamo del FMI entre 1985 y 2014 y encuentra "poca evidencia de una transformación fundamental de la condicionalidad del FMI").

69 Kentikelenis et al., supra nota 28, e758. 
la protección social garantizando pisos de gasto social, ${ }^{70}$ la materialización de estas opiniones está en duda. ${ }^{71} \mathrm{~A}$ pesar de una serie de reformas a principios de este siglo, incluido un esfuerzo por centrarse en los objetivos del programa dentro del límite de sus competencias en respuesta a las críticas sobre el alcance y el nivel de "intrusión", tanto el número como el alcance de las condicionalidades parecen ser crecientes. ${ }^{72}$ Las iniciativas posteriores destinadas a aumentar la flexibilidad del enfoque del FMI para el ajuste estructural fueron seguidas de un esfuerzo por racionalizar las condicionalidades. ${ }^{73}$ Los ajustes más recientes en este sentido incluyen una mayor consideración de temas como la desigualdad económica y de género. ${ }^{74}$

Incluso cuando el FMI ha asumido nuevos compromisos serios con importantes políticas sociales, no ha ido lo suficientemente lejos en la integración de esos compromisos en las reformas económicas propuestas que incluye en las condicionalidades. Por ejemplo, el compromiso del FMI de abordar la desigualdad de género es claramente una iniciativa importante. Sin embargo, el autor ha destacado anteriormente que el FMI debe ir más allá de los esfuerzos desplegados únicamente para cerrar la brecha de género en la participación de la fuerza laboral. ${ }^{75}$ Un compromiso con la igualdad de género también debe orientar los cambios en la cobertura de los beneficios de protección social, el espacio fiscal para los servicios sociales

70 Indep. Evaluation Off., IMF, The IMF and Social Protection 6 (2017); IMF, A Strategy for IMF Engagement on Social Spending, Policy Paper 7 (junio de 2019) (respondiendo).

71 Ver infra nota 81.

72 Gino Brunswijck, Eur. Network on Debt and Dev., "Unhealthy Conditions: IMF Loan Conditionality and Its Impact on Health Financing", 3, 5-6 (2018).

$73 \mathrm{Id}$.

74 Id. 5; IMF Gender Advisory Grp., How to Operationalize Gender Issues in Country Work (2018).

75 Experto Independiente en Deuda y Derechos Humanos, “Report on the Impact of Economic Reforms and Austerity Measures on Women's Human Rights, 17-19, U.N. Doc. A/73/179 (18 de Julio de 2018). 
y las inversiones en infraestructura sostenible e inclusiva de género. ${ }^{76}$

Algunos argumentan que las afirmaciones del FMI sobre su transformación ${ }^{77}$ no se parecen más que a un ejercicio superficial de "cambio de marca" en lugar de un esfuerzo por promover cambios más profundos en las prácticas existentes. ${ }^{78}$ Por ejemplo, un estudio que compara las políticas recomendadas antes de 2011 con prescripciones más recientes en cuatro Estados de la región de Oriente Medio y África del Norte revela que las políticas del FMI no han cambiado drásticamente de un período a otro. ${ }^{79} \mathrm{Y}$ en su World Economic Outlook de 2019, el FMI pidió una vez más reformas estructurales centradas en la liberalización y la desregulación, particularmente en los países de bajos ingresos, para promover el crecimiento económico. ${ }^{80}$ Los cambios en las políticas laborales y sociales no han encontrado su lugar en los esfuerzos de promoción del FMI ni se derivan sistemáticamente de la implementación a nivel de país de los segmentos de su programa destinados a la protección social, como los pisos de gasto social. ${ }^{81}$

Las condicionalidades que continúan incluyéndose no solo han crecido en número, sino que también se han ampliado las áreas de política que cubren. ${ }^{82}$ La Revisión del Diseño y la

\footnotetext{
76 Id.

77 Ver FMI. Development Committee: The Managing Director's Written Statement 2-4 (19 de octubre de 2019) (citando las prioridades de política del FMI y reformas diseñadas para apoyar mejor a las economías emergentes y en desarrollo en el desarrollo de políticas fiscales estables).

78 Kentikelenis et al., supra nota 68.

79 Mohammed Mossallem, Bretton Woods Project, "The IMF in the Arab World: Lessons Unlearnt", 6-13, 15 (noviembre de 2015).

80 FMI. Global Manufacturing Downturn, Rising Trade Barriers, World Economic Outlook 96-103 (octubre de 2019).

81 Kentikelenis et al., supra nota 68 (explicando que el FMl continúa abogando por la liberalización del mercado laboral y que los pisos de gasto social a menudo no se alcanzan). 82 Brunswijck, supra nota 72.
} 
Condicionalidad de los Programas del FMI de 2018 señaló el marcado aumento en el volumen de las condiciones estructurales en los programas entre 2011 y 2017. ${ }^{83}$ Además, veintitrés de los veintiséis programas de préstamos del FMI aprobados entre 2016 y 2017 estaban condicionados a la consolidación fiscal: políticas diseñadas para reducir el déficit y la deuda de los países, y un sello de austeridad. ${ }^{84}$

Un examen detallado de los acuerdos con el FMI celebrados entre 1980 y 2014 también reveló que el número de condiciones vinculadas a los préstamos había aumentado y su alcance se había ampliado. ${ }^{85} \mathrm{Si}$ bien las condicionalidades relacionadas con áreas centrales de política económica representaron casi el $87 \%$ del número total de condicionalidades, el $13 \%$ restante se relacionó con la privatización de empresas estatales, cuestiones laborales en el sector público y privado, reformas institucionales y políticas para la reducción de la pobreza. ${ }^{86} \mathrm{~A}$ pesar de la creencia generalizada por parte de quienes respaldan estas políticas de que las reformas laborales impulsadas por la austeridad dan como resultado la desregulación del mercado laboral y, por lo tanto, estimulan el crecimiento económico, tales políticas no necesariamente han contribuido al crecimiento económico o al aumento del empleo, por no hablar de impacto negativo en los derechos humanos. ${ }^{87}$

Como señaló recientemente el autor en una carta abierta dirigida al presidente del Banco Mundial en relación con el borrador del Informe sobre el Desarrollo Mundial 2019, muchas cuestiones contemporáneas, como la informalidad laboral, la ruptura de los

\footnotetext{
83 FMI, 2018 Review of Program Design and Conditionality 35 (mayo de 2019).

84 Brunswijck, supra nota 72.

85 Stubbs \& Kentikelenis, supra nota 67.

86 La privatización de empresas estatales es la más común, seguida de cuestiones laborales. Id.

87 Principios Rectores, supra nota 3; ver infra Partes II y III (explicando la teoría económica defectuosa en la que se basa la austeridad y las graves violaciones de derechos humanos que se derivan de su imposición).
} 
contratos sociales y la desigualdad de género e ingresos, "se han visto agravadas por la austeridad y reformas laborales anteriores, incluida la congelación o reducción de los salarios mínimos, la desregulación del mercado laboral, la privatización de la seguridad social y los planes de protección social específicos". ${ }^{88}$

Además, el enfoque de "maximización de la financiación para el desarrollo", lanzado recientemente por el Banco Mundial y cuyo objetivo es fomentar la inversión del sector privado para permitir el desarrollo sostenible, confirma que el Banco sigue promoviendo el "aprovechamiento del sector privado" cuando está disponible, con el fin de limitar la "deuda pública y los pasivos contingentes". ${ }^{89}$ Trasladar la prestación de servicios esenciales a empresas con ánimo de lucro puede afectar negativamente los derechos humanos y la viabilidad del sector público. $^{90}$

Un estudio de las condicionalidades vinculadas al financiamiento del desarrollo del Banco Mundial en 2017 destacó la influencia del Banco en las "políticas económicas internas" y la "configuración de las instituciones" en los países en desarrollo. ${ }^{91}$ El estudio reveló que, a diferencia del FMI, el número de condicionalidades impuestas por el Banco Mundial disminuyó en comparación con años anteriores. ${ }^{92}$ El estudio continuó afirmando, sin embargo, que incluso "una pequeña cantidad de condiciones

88 Carta del Experto Independiente en Deuda y Derechos Humanos a Jim Yong Kim, Pres., Banco Mundial (3 de agosto de 2018).

89 WBG, Maximizing Finance for Development, Brief 1 (2018); ver también Informe del Relator Especial sobre Extrema Pobreza y Derechos Humanos, 20, U.N. Doc. A/73/396 (Sept. 26, 2018) (explicando cómo, de acuerdo con la agenda de Maximización del financiamiento para el desarrollo, "las empresas rentables se reservarán al sector privado, mientras que las actividades no rentables se financiarán con fondos públicos").

90 Informe del Relator Especial sobre Extrema Pobreza y Derechos Humanos, supra 89.

91 El estudio examinó 56 operaciones del Banco Mundial en 43 países. Gino Brunswijck, Eur. Network on Debt \& Dev., "Flawed Conditions: The Impact of the World Bank's Conditionality on Developing Countries" 2 (abril de 2019).

92 Id. 
de política económica controvertidas puede ser muy perjudicial para la agenda de desarrollo de un país". ${ }^{93}$ Además, casi el $28 \%$ de las condiciones enumeradas estaban "destinadas a aumentar el papel del sector privado" en todas las áreas de política. ${ }^{94}$

\section{II. ¿Qué es lo que realmente hace la austeridad a la economía?}

Inmediatamente después de la crisis financiera mundial de 2008, se reconoció ampliamente que era necesario un estímulo económico internacional para superar los impactos sociales y económicos de la crisis de la recesión. ${ }^{95}$ En esta situación, como señala un estudio reciente, el FMI normalmente habría recomendado que se impongan medidas de austeridad a la contratación de fondos públicos. ${ }^{96}$ En cambio, el FMI alentó el estímulo fiscal, temiendo un empeoramiento de la situación económica. ${ }^{97}$ Este enfoque prevaleció durante dos años después de la crisis, pero poco después surgió una tendencia generalizada de consolidación fiscal, con dos tercios de los países del mundo instituyendo medidas de austeridad. ${ }^{98} \mathrm{Al}$ afectar el crecimiento económico y la igualdad y los recursos públicos por definición, estas medidas tienen un impacto negativo en la realización de los derechos humanos, sin embargo, las IFI las

$\begin{array}{ll}93 & \text { Id } \\ 94 & \text { Id } \\ 95 & \end{array}$

95 Camilla Anderson, IMF Spells Out Need for Fiscal Stimulus, IMF (29 de diciembre de 2008), https://www.imf.org/en/News/Articles/2015/09/28/04/53/soint122908a [https://perma.cc/ YH64-NTLE].

96 Isabel Ortiz et al., "The Decade of Adjustment: A Review of Austerity Trends 2010-2020 in 187 Countries" 8 (Int'I Lab. Org., Working Paper No. 53, 2017).

97 Anderson, supra nota 95; Alasdair Scott, Making Fiscal Stimulus Effective During Downturns, IMF (Oct. 2, 2008), https://www.imf.org/en/News/Articles/2015/09/28/04/53/ sores100208b [https://perma.cc/2E4K-8U8R] (promover estímulos fiscales "oportunos, focalizados y temporales").

98 Isabel Ortiz \& Matthew Cummins, "Austerity: The New Normal A Renewed Washington Consensus" 2010-24 11 (Initiative for Pol'y Dialogue et al., Working Paper, oct. 2019). 
siguen recomendando. ${ }^{99}$ Por tanto, es fundamental deconstruir la teoría económica que apoya la austeridad.

\section{A. Efectos de la austeridad en el crecimiento, la sostenibilidad de la deuda y la igualdad}

La evidencia muestra el impacto adverso de la austeridad en la economía en tiempos de recesión. Los/as economistas han destacado que cuando la economía está débil, el padecimiento se prolonga por los efectos perjudiciales de la contracción fiscal en varios servicios públicos. ${ }^{100}$ Un cuerpo importante de literatura demuestra que las medidas de austeridad no contribuyen a la recuperación económica, de hecho tienen consecuencias negativas para la economía al tiempo que aumenta la deuda pública como porcentaje del producto interno bruto (PBI). ${ }^{101}$ Un estudio que examinó la gravedad de las medidas de austeridad adoptadas por un grupo de países europeos entre 2009 y 2013 estableció que cuanto más duras eran las medidas de austeridad, menor era la tasa de crecimiento del PBI. ${ }^{102}$

Como estos/as académicos/as y también otros han demostrado en repetidas ocasiones, la austeridad no resulta en crecimiento

\footnotetext{
99 Ver infra Parte III (que describe los impactos negativos de la austeridad en los derechos humanos).
}

100 Alan M. Taylor, "When is the Time for Austerity?", Ctr. for Econ. \& Pol'y Rsch. (10 de julio de 2013), https://voxeu.org/article/when-time-austerity [https://perma.cc/M7FV-3JDP]; Òscar Jordà \& Alan M. Taylor, "The Time for Austerity: Estimating the Average Treatment Effect of Fiscal Policy", 126 Econ. J. 219, 220 (2016) (se encuentra que "en promedio, las consolidaciones fiscales generan un lastre para el crecimiento del PBI"). En palabras de Keynes: "El boom, no la recesión, es el momento indicado para la austeridad fiscal", 21 John Maynard Keynes, Collected Writings, 1931-1939 390 (Donald Moggridge ed., 1937).

101 W. D. McCausland \& Ioannis Theodossiou, "The Consequences of Fiscal Stimulus on Public Debt: A Historical Perspective", 40 Cambridge J. Econ. 1103, 1114 (2016).

102 Robert Skidelsky \& Nicolo Fraccaroli, Austerity vs Stimulus: The Political Future of Economic Recovery 45-47 (2017); ver también Axel Dreher, "IMF and Economic Growth: The Effects of Programs, Loans and Compliance with Conditionality", 34 World Dev. 769, 781 (2006) (encontrando que "el impacto del cumplimiento de la condicionalidad sobre el crecimiento es cuantitativamente pequeño"). 
económico. ${ }^{103}$ Por ejemplo, tras la última crisis mundial, la Conferencia de las Naciones Unidas sobre Comercio y Desarrollo (UNCTAD) reiteró que la austeridad no era sinónimo de crecimiento, confirmando sus resultados y predicciones anteriores. ${ }^{104}$

La organización también destacó que el ajuste en Europa y una dependencia excesiva de la política monetaria han afectado la estabilidad de los mercados financieros internacionales, han contribuido al desequilibrio financiero en las economías en desarrollo y, en gran medida, no han logrado impulsar la demanda de los/as consumidores/as. ${ }^{105}$

Teniendo en cuenta las consideraciones empíricas, no es posible concluir que la contracción fiscal provoque la expansión económica. ${ }^{106}$ Algunos/as académicos/as han descubierto que los casos utilizados para demostrar los supuestos efectos positivos de la austeridad, como los de Dinamarca o Irlanda, ${ }^{107}$ deberían considerarse casos de advertencia en lugar de modelos válidos externamente, por no hablar de los problemas de derechos humanos que han surgido en esos países. ${ }^{108} \mathrm{Si}$ bien se comparó la experiencia de Irlanda en la década de 1980 con

103 Jordà \& Taylor, supra nota 100.

104 Press Release, U.N. Conference on Trade and Development, "Austerity Did Not Lead to Growth; Supportive Government Policies Are Still Needed", UNCTAD Report Says, U.N. Press Release UNCTAD/PRESS/PR/2012/030 (12 de septiembre de 2012).

105 U.N. Conf. on Trade \& Dev., Trade and Development Report 162 (2016).

106 Ver Robert Boyer, "The Four Fallacies of Contemporary Austerity Policies: The Lost Keynesian Legacy", 36 Cambridge J. Econ. 283, 308 (ene. 2012).

107 Giavazzi y Pagano, por ejemplo, han argumentado que las experiencias de Dinamarca e Irlanda con la contracción fiscal apoyan la noción de que un efecto expansivo seguirá a tales políticas. Francesco Giavazzi \& Marco Pagano, "Can Severe Fiscal Contractions Be Expansionary? Tales of Two Small European Countries" (Nat'I Bureau Econ. Rsch., Working Paper No. 3372, 1990).

108 Ver Mark Blyth, Austerity: The History of a Dangerous Idea 236 (2013) (señalando que el gasto social y de bienestar de Irlanda se ha reducido como resultado de las medidas de austeridad); ver también Stephen Kinsella, "Is Ireland Really the Role Model for Austerity?", 36 Cambridge J. Econ. 223, 234 (2012) (prediciendo que las medidas de austeridad de Irlanda 
la adopción mundial de medidas de austeridad después de la última crisis mundial, se sugirió que el impacto de la austeridad en el crecimiento no era tan claro como se había proyectado y, a corto plazo, habría sido difícil ver la recuperación de Irlanda "solo como resultado de las medidas de austeridad". ${ }^{109}$

El último Examen del FMI sobre el Diseño y la Condicionalidad de los Programas destaca que, entre 2011 y 2017, tres cuartas partes de los programas implementados con el apoyo del FMI fueron al menos parcialmente exitosos, pero que "los supuestos de crecimiento a menudo eran demasiado optimistas". ${ }^{110}$ En respuesta a estos hallazgos, el FMI sugirió que mejoraría la credibilidad de estos programas. Recomendó, entre otras cosas, la reevaluación de ciertas "compensaciones en el diseño del programa", aconsejando, por ejemplo, una "condicionalidad fiscal más granular" promovida sobre una base más casuística y un "análisis de sostenibilidad de la deuda más preciso". ${ }^{111}$

Un aumento de la desigualdad y el desempleo a menudo sigue a la introducción de la consolidación fiscal. Como ha señalado el FMI, entre 1978 y 2009, las medidas de consolidación fiscal instituidas en diecisiete países miembros de la OCDE afianzaron significativamente las desigualdades estructurales, además de reducir los ingresos salariales y contribuir a un aumento del desempleo a largo plazo. ${ }^{112}$

La consiguiente amenaza a la cohesión social ya es visible en varios países. En algunos casos, las medidas de austeridad

conducirán a "grandes recortes en los salarios y las pensiones y transferencias de asistencia social").

109 Kinsella, supra nota 108.

110 FMl Review of Program Design and Conditionality, supra nota 83.

111 Laurence Ball et al., The Distributional Effects of Fiscal Consolidation 10 (IMF, Working Paper, No. WP/13/151, 2013).

112 Laurence Ball et al., The Distributional Effects of Fiscal Consolidation 10 (IMF, Working Paper, No. WP/13/151, 2013). 
han contribuido brevemente al crecimiento económico, en parte debido a la alta demanda interna, y varios países adoptaron medidas de austeridad de manera preventiva después de la crisis. ${ }^{113}$ Desde entonces, se estima que se han adoptado medidas de austeridad de diversas formas en dos tercios de los países del mundo. ${ }^{114}$ Lo/as académico/as han observado que los límites y recortes salariales, junto con los subsidios más bajos, son más comunes en los países en desarrollo, mientras que las reformas laborales y de pensiones son más evidentes en los países de ingresos altos. ${ }^{115}$ Todo esto tiene claras y profundas implicaciones para el derecho a la protección social, que tiene una importancia renovada en el contexto de la pandemia.

A estas alturas, no hay duda sobre los posibles impactos de las medidas de austeridad en los derechos humanos. En 2016, el Comité de Derechos Económicos, Sociales y Culturales destacó los efectos potenciales de las medidas de austeridad en una serie de derechos humanos, incluidos los derechos laborales y los derechos a la alimentación, la vivienda y la seguridad social. ${ }^{116}$ Además, un documento de 2015 destacó específicamente el impacto de la consolidación fiscal en la reducción de los ingresos agregados de una economía y sus efectos especialmente severos en el segmento más pobre de la población. ${ }^{117}$

\footnotetext{
113 OHCHR, "Report on Austerity Measures and Economic and Social Rights", párr. 5 (2013) (explicando que dichas medidas fueron adoptadas para reducir los déficits fiscales de manera preventiva con el fin de "evitar reacciones negativas de los mercados financieros").

114 Ortiz et al., supra nota 96.

115 Id.

116 Public Debt, Austerity Measures, \& ICESCR, supra nota 58, 1 (señalando que estos derechos, entre otros, pueden verse afectados negativamente si los programas de austeridad "no se implementan con pleno respeto por las normas de derechos humanos [0] no toman en cuenta las obligaciones de los Estados hacia los titulares de derechos").

117 Davide Furceri et al., "Fiscal Consolidation and Inequality in Advanced Economies: How Robust Is The Link?", en Inequality and Fiscal Policy, 141, 155-56 (Benedict Clements et al. eds., 2015).
} 
A menudo se ha informado sobre el impacto de las medidas de austeridad en los derechos humanos y la desigualdad, al tiempo que se ha explicado que la desigualdad económica es tanto un resultado como un factor que contribuye a las crisis económicas. ${ }^{118} \mathrm{La}$ evidencia sugiere que después de la crisis financiera de 2008, las reformas laborales convencionales relacionadas con la austeridad no ayudaron a la recuperación ni aumentaron el acceso al empleo ni ayudaron a hacer realidad otros derechos sociales. ${ }^{119}$ Se han extraído conclusiones similares con respecto al impacto de la austeridad en los derechos humanos en general y en los derechos de la mujer en particular. ${ }^{120}$

\section{B. Deconstrucción de la teoría de la "austeridad expansiva"}

Si bien el tema de la consolidación fiscal ha estado en el centro de las investigaciones y debates durante años, una nueva ola de estudios económicos ha prestado especial atención a su impacto en el crecimiento económico y su relevancia en tiempos de crisis. ${ }^{121}$ Los efectos expansivos de las políticas económicas ortodoxas han sido la idea propulsora detrás de las condicionalidades, pero algunos/as académicos/as han sugerido últimamente que la austeridad tendría un efecto "expansivo", argumentando que la consolidación fiscal contribuiría a la recuperación económica. ${ }^{122}$ Por ejemplo, los resultados clave de un estudio reciente

\footnotetext{
118 Ver Juan Pablo Bohoslavsky, "Economic Inequality, Debt Crises and Human Rights", 41 Yale Journal Int'I L., 177-79 (2016) (que describe el impacto de las medidas de austeridad en los derechos humanos y la desigualdad).

119 Informe del Experto Independiente en Deuda y Derechos Humanos sobre la misión a la Unión Europea, supra nota 63.

120 Informe del Experto Independiente en Deuda y Derechos Humanos sobre el impacto de las reformas económicas y las medidas de austeridad sobre los derechos humanos de las mujeres, supra nota 75.

121 Robert Skidelsky \& Nicolò Fraccaroli, Introduction to Austerity vs Stimulus: The Political Future of Economic Recovery, supra nota 102.

122 Alberto F. Alesina et al., "What Do We Know About the Effects of Austerity?" 5 (Nat'I Bureau Econ. Rsch., Working Paper No. 24246, 2018).
} 
sugieren que "[un] ajuste fiscal promedio basado en recortes de gastos tiene costos de producción muy pequeños y en algunos casos son expansivos". ${ }^{123}$

Este enfoque generalmente se conoce como la teoría de la "contracción fiscal expansiva". ${ }^{124}$ Según sus defensores/as, evitar un mayor aumento del déficit fiscal en momentos de crisis permite una reactivación económica. ${ }^{125} \mathrm{~A}$ pesar de la evidencia generalizada que muestra que la austeridad no contribuye a la recuperación o el crecimiento económicos, ${ }^{126}$ esta idea parece seguir influyendo en el pensamiento económico dominante en un grado desproporcionado. ${ }^{127}$

Sin embargo, otros/as economistas han argumentado que el déficit fiscal puede ser útil para la recuperación económica y que el estímulo y las medidas redistributivas pueden ir de la mano, dando resultados positivos desde el punto de vista de los derechos humanos y a nivel económico. ${ }^{128}$ Por tanto, la justificación que respalda el recurso a la austeridad se basa en la idea simplificada de que, en tiempos de recesión económica, debe evitarse un mayor déficit fiscal. Aumentar (o mantener) el gasto público, según la teoría, resultaría en una profundización del déficit fiscal, reduciendo así el gasto de los/as consumidores/as, según la escuela "Ricardiana", o impactando negativamente las inversiones, según la "nueva escuela clásica". ${ }^{129}$

\footnotetext{
123 Id.

124 Skidelsky \& Fraccaroli, supra nota 121.

125 Alesina et al., supra nota 122.

126 Ver Jordà \& Taylor, supra nota 100.

127 Ver Skidelsky \& Fraccaroli, supra nota 121.

128 Ver Robert Skidelsky, Stimulus, "Not Austerity, is the Key to Global Economic Recovery", en Austerity Vs. Stimulus: The Political Future of Economic Recovery, supra nota 102 (argumentando a favor del estímulo fiscal y una expansión de los déficits fiscales en tiempos de crisis, y sugiriendo que "las medidas [r]edistributivas van bastante bien con las políticas de estímulo, porque se puede esperar que aumenten la demanda agregada en el corto plazo").

129 Skidelsky \& Fraccaroli, supra nota 121, xviii.
} 
Si bien los/as economistas basan sus resultados en una serie de elementos explicativos, el impacto de los déficits fiscales en el nivel de confianza (ya sea de consumidores/as o inversores/as) es sin duda el más cuestionable. ${ }^{130}$ Tras afirmar que el déficit fiscal necesariamente afecta la confianza de las empresas y los/as consumidores/as en la economía, varios/as economistas afirman que los déficits provocan una disminución del gasto privado y la inversión empresarial, lo que reduce el potencial de recuperación económica. ${ }^{131}$ En su opinión, la austeridad contribuye a restablecer la confianza e induce el crecimiento económico. ${ }^{132}$ Estas suposiciones han sido cuestionadas muchas veces. ${ }^{133} \mathrm{El}$ problema principal radica en la metodología de investigación utilizada en los estudios que apoyan la austeridad expansiva. En definitiva, la variable utilizada para realizar estudios empíricos sobre los efectos de la austeridad en la economía no está correctamente calificada y, por tanto, impacta de manera significativa los resultados de la investigación económica. ${ }^{134} \mathrm{Si}$ bien la consolidación fiscal es considerada una variable exógena por los/as defensores/as de la austeridad expansiva, otros/as economistas han demostrado que este enfoque está fundamentalmente sesgado y que la consolidación fiscal debe considerarse endógena. ${ }^{135}$

130 Alesina y otros también examinan las políticas, la oferta de trabajo y los efectos de red que las acompañan como elementos explicativos de sus resultados empíricos sobre los efectos de la austeridad. Alesina et al., supra nota 122, págs. 8-12.

131 Skidelsky \& Fraccaroli, supra nota 121.

132 Id.

133 Ver, por ejemplo, id. ("En el mundo real, sin embargo, es extremadamente difícil pronosticar la reacción de las empresas a las políticas fiscales".) Christian Breuer, "Expansionary Austerity and Reverse Causality: A Critique of the Conventional Approach", 3-9 (Inst. for Econ. Thinking, Working Paper No. 98, 2019), https://www.ineteconomics.org/uploads/papers/ WP_98-Breuer.pdf [https://perma.cc/7UTJ-DJP5] (identifica críticas previas a los estudios económicos que sustentan estas teorías y señala errores metodológicos que distorsionan los resultados de estos estudios).

134 Breuer, supra nota 133.

135 Ver Alberto Alesina, "Some Evidence in Favour of Austerity", en Austerity vs. Stimulus: The Political Future of Economic Recovery supra nota 102 (tratando la consolidación fiscal 
Una variable exógena es un instrumento económico que se utiliza para identificar una variable fuera del modelo económico (como la ocurrencia de un shock), mientras que una variable endógena está determinada por el propio modelo económico o no puede ser considerada como un fenómeno externo. ${ }^{136}$

En el caso del FMI, la implementación de medidas de austeridad en realidad puede "predecirse utilizando controles macroeconómicos predeterminados" y, por lo tanto, no puede calificarse de exógena. ${ }^{137}$ Es decir, algunos estudios económicos, basados en fallas empíricas, han concluido erróneamente que la austeridad tiene un efecto "expansivo", malinterpretando así su papel en la potencial recuperación económica. ${ }^{138}$

\section{El impacto del ajuste en los derechos humanos}

Como se describe en las Partes I y II, las IFI han asesorado, promovido e incluso presionado a los países para que adopten la consolidación fiscal, incluyéndola con frecuencia entre las condicionalidades asociadas a los préstamos. ${ }^{139} \mathrm{Al}$ mismo tiempo, las devastadoras consecuencias de la consolidación fiscal sobre los derechos humanos son bien conocidas y están documentadas. Los órganos de tratados, los/as titulares de mandatos de procedimientos especiales, las organizaciones de la sociedad

como una variable exógena). Ver Breuer, supra nota 133, en 23 (sugiriendo que la consolidación fiscal debería ser tratada como endógena).

136 Alesina, supra nota 135.

137 Taylor, supra nota 100; ver también Jordà \& Taylor, supra nota 100, en 228-31 (evaluando "si la variable narrativa del FMI podría ser un instrumento legítimo" de capacidad predictiva en macroeconomía).

138 Ver Breuer, supra nota 133 (que introduce el "método Blanchard" para corregir los supuestos equivocados del método de ajuste cíclico convencional establecido por Alesina y Perotti, que apoya la noción de austeridad expansiva).

139 Ver FMI Review of Program Design and Conditionality, supra nota 83, en 1, 25, 50 (donde se encuentra la necesidad de una "condicionalidad fiscal más granular" y una "mayor adaptación" para lograr una mayor calidad de ajuste fiscal y mejorar la calidad del gasto público sin sobrecargar la posición macroeconómica de los países). 
civil y los/as académicos/as han informado en repetidas ocasiones sobre los impactos dañinos, tanto reales como potenciales, de la consolidación fiscal en una amplia gama de derechos humanos y en grupos específicos, subrayando que las personas que enfrentan desigualdades acumulativas e interseccionales se ven afectadas de manera desproporcionada. ${ }^{140}$

Una y otra vez, los/as expertos/as han demostrado cómo las condicionalidades, en particular las que prescriben políticas de consolidación fiscal y ajuste estructural, pueden socavar directamente el disfrute de los derechos económicos, sociales y culturales. ${ }^{141}$ A continuación se presentan varios ejemplos que ilustran cómo los efectos negativos de la austeridad sobre el crecimiento económico, la sostenibilidad de la deuda y la igualdad económica se traducen fácilmente en consecuencias adversas para los derechos humanos.

Para empezar, las reformas laborales implementadas en el contexto de los programas de ajuste estructural han contribuido a la erosión de los derechos laborales colectivos e individuales, y la implementación de topes salariales o límites laborales ha afectado el derecho a un trabajo y condiciones laborales justas y favorables. ${ }^{142}$ Las reformas laborales también pueden afectar negativamente a la igualdad de género. Por ejemplo, los recortes

\footnotetext{
140 Ver, por ejemplo, Rep. sobre medidas de austeridad y derechos económicos y sociales, supra nota 113 (perfilando los efectos de las medidas de austeridad sobre las mujeres, los migrantes y las personas mayores en particular); véase, en general, Economic and Social Right after the Global Financial Crisis (Aoife Nolan ed., CUP, 2014) (donde se señala el impacto dañino de las políticas de contracción fiscal nacionales y supranacionales en poblaciones con vulnerabilidades y desventajas preexistentes).

141 Véase, por ejemplo, el informe del Experto Independiente en Deuda y Derechos Humanos sobre la misión a la Unión Europea, supra nota 63, (destacando preocupaciones de derechos humanos como el aumento del número de personas en riesgo de pobreza, exclusión social y falta de vivienda, así como como un mayor riesgo de malestar social e ideologías extremistas como resultado de las medidas de austeridad en Europa); ver el informe del Experto Independiente en Deuda y Derechos Humanos sobre la misión a Grecia, supra nota 5 (que detalla el impacto de las medidas de austeridad en los derechos económicos, sociales y culturales en ese país).
}

142 Stubbs \& Kentikelenis, supra nota 67. 
obligatorios en los empleos del sector público han contribuido al aumento de la informalidad, la disminución de las prestaciones por desempleo, el deterioro de las protecciones sociales y el aumento de las cargas en forma de trabajo de cuidado no remunerado para las mujeres. ${ }^{143}$

Además de la consolidación fiscal, las reformas específicas propuestas en situaciones similares pueden ser motivo de especial preocupación. Por ejemplo, al acuerdo de préstamo más reciente de Ucrania con el FMI, ${ }^{144}$ se adjuntaron una serie de condiciones, incluida la privatización de un número significativo de empresas de propiedad estatal. Al perseguir la privatización, los países deben contar con mecanismos efectivos para asegurar que los resultados económicos de este proceso beneficien a la población más desfavorecida o en riesgo de caer en la pobreza, en lugar de abordar exclusivamente la consolidación fiscal. Esto se debe en parte al hecho de que la privatización puede poner en riesgo el acceso a una variedad de servicios, incluidos servicios esenciales como el agua y la electricidad. ${ }^{145}$ Además, las medidas que tienen como resultado la reducción de subsidios o que afectan el precio de bienes específicos pueden tener un efecto directo: por ejemplo, una disminución o eliminación de los subsidios al gas y al combustible puede tener graves

143 Informe del Experto Independiente en Deuda y Derechos Humanos sobre el impacto de las reformas económicas y las medidas de austeridad sobre los derechos humanos de las mujeres, supra nota 75.

144 Informe del Experto Independiente en Deuda y Derechos Humanos sobre la visita a Ucrania, 29, 83-86, U.N. Doc. A/HRC/40/57/Add.1 (31 de diciembre de 2018).

145 Este es particularmente el caso cuando se privatizan proyectos de infraestructura, según un informe de 2018 presentado por el Relator Especial sobre pobreza extrema y derechos humanos, 31-37, U.N. Doc. A / 73/396 (26 de septiembre de 2018). La privatización de la infraestructura pone en desventaja a lo/as pobres porque, en general, "están en una mala posición para pagar, no pueden permitirse el uso de muchos servicios y, a menudo, viven en áreas distantes o desatendidas", 36. Además, es mucho menos probable que los servicios que incluyen "[agua, saneamiento, electricidad, carreteras, transporte, educación, atención médica, servicios sociales y financieros se presten de manera adecuada 0 en niveles de buena calidad a los pobres", Id. 
consecuencias para los medios de vida y poner en peligro la realización de derechos económicos, sociales y culturales. ${ }^{146}$

Las medidas adoptadas para orientar mejor a los/as beneficiarios/as de los sistemas de protección social también pueden ser motivo de preocupación. En Túnez, por ejemplo, se destacó que reorientar los beneficios exclusivamente a los/as más carenciados/as puede resultar en una cobertura inadecuada para otras personas en situaciones de pobreza. ${ }^{147}$

Asimismo, en sus Observaciones Finales sobre Portugal, el Comité de los Derechos de las Personas con Discapacidad expresó su preocupación por el impacto de las medidas de austeridad en los servicios de apoyo disponibles para las personas con discapacidad, subrayando que "en ausencia de redes de apoyo o asistencia familiar" en riesgo de vivir en pobreza o pobreza extrema. ${ }^{148}$

De manera similar, el Comité para la Eliminación de la Discriminación contra la Mujer ha subrayado que, en general, los recortes en los servicios públicos realizados en el contexto de las crisis económicas tienen "consecuencias negativas específicas" para las mujeres y las niñas, incluida la posibilidad de excluirlas de la educación y sobrecargarlas con más trabajo de cuidado no remunerado. ${ }^{149}$

146 Informe del Experto Independiente en Deuda y Derechos Humanos sobre la visita a Ucrania, supra nota 144. De conformidad con su acuerdo de préstamo con el FMI de 2014, Ucrania elevó el costo del gas residencial al precio de mercado, eliminando al hacerlo los subsidios de larga data. Id. en 37. La medida condujo a precios mucho más altos para "bienes y servicios relacionados con el uso de combustible", afectó negativamente "no solo a los grupos marginados sino también a la llamada clase media" y tuvo un impacto desproporcionado en las poblaciones rurales, Id.

147 Informe del Experto Independiente en Deuda y Derechos Humanos sobre la visita a Túnez, 38, U.N. Doc. A/HRC/37/54/Add.1 (7 de marzo de 2018).

148 Informe del Experto Independiente en Deuda y Derechos Humanos sobre el impacto de las reformas económicas y las medidas de austeridad sobre los derechos humanos de las mujeres, supra nota 75.

149 Comm. on the Elimination of Discrimination Against Women, General Recommendation No. 36 on the Right of Girls and Women to Education, 37-38, 53 U.N. Doc. CEDAW/C/GC/36 
Al subrayar que el actual sistema económico mundial se sustenta en la desigualdad de género y las múltiples formas de discriminación de género, se ha destacado que las medidas de consolidación fiscal impulsadas por la austeridad y las reformas económicas, como el fomento de la flexibilización del mercado laboral, las reducciones en la cobertura de los beneficios y servicios de protección social, los recortes en los empleos del sector público y la privatización de los servicios tienden a afectar negativamente a las mujeres más que a los hombres. ${ }^{150}$

En sus Observaciones Finales sobre Chipre, el Comité de Derechos Económicos, Sociales y Culturales señaló con preocupación "la continua y significativa disminución del gasto público, en particular en las áreas de protección social, vivienda, salud y educación, en el marco de las medidas de consolidación fiscal". ${ }^{151}$ También destacó el "impacto desproporcionadamente adverso" de tales medidas en el disfrute de los derechos económicos, sociales y culturales, especialmente para las personas y grupos desfavorecidos y marginados. ${ }^{152}$

Se ha observado un aumento en las condicionalidades de reducción de la pobreza en los últimos años, pasando de alrededor del $1 \%$ en 1998 al $5 \%$ del número total de condicionalidades en $2014 .{ }^{153}$ Sin embargo, persisten brechas y, como señalan

(27 de noviembre de 2017). Según la CEDAW, cuando la privatización de la educación obliga a los padres/madres a pagar para enviar a sus hijos/as a la escuela, los/as padres/madres pobres tienden a priorizar el envío de niños a la escuela sobre las niñas, debido en parte a la percepción de que los niños "podrán acceder a mejores empleos oportunidades después de la escolarización que las niñas, y en parte debido a estereotipos que colocan a las niñas en la esfera doméstica", Id.

150 Informe del Experto Independiente en Deuda y Derechos Humanos sobre el impacto de las reformas económicas y las medidas de austeridad sobre los derechos humanos de las mujeres, supra nota 75.

151 Comm. on Econ., Soc. \& Cultural Rts., Concluding Observations on the Sixth Periodic Rep. of Cyprus, 11, U.N. Doc. E/C.12/CYP/CO/6 (28 de octubre 2016).

$152 \mathrm{Id}$.

153 Stubbs \& Kentikelenis, supra nota 67 
los/as académicos/as, estas condicionalidades se tratan como menos importantes para asegurar acuerdos de préstamo que las condiciones macroeconómicas, incluida la consolidación fiscal. ${ }^{154}$ Si bien las IFI insistirán en que los países cumplan objetivos fiscales específicos a corto plazo para garantizar los términos de sus acuerdos de préstamo, los objetivos de reducción de la pobreza tienden a ser tratados como no vinculantes y, a menudo, están sujetos a negociaciones mucho mayores. ${ }^{155}$ Como resultado, a pesar del establecimiento de metas de gasto prioritarias para la reducción de la pobreza, a menudo siguen sin cumplirse, ${ }^{156} \sin$ mencionar que las condicionalidades para la reducción de la pobreza pueden no cumplir con las normas de derechos humanos. ${ }^{157}$

La reducción de la pobreza y otras condicionalidades afectan a sectores sociales específicos con importantes consecuencias potenciales para los derechos humanos. Un ejemplo claro es el impacto potencial de la consolidación fiscal y los recortes relacionados en el gasto público en el sector de la salud. Por ejemplo, en Chad entre 2013 y 2017 el presupuesto del sector de la salud se redujo a la mitad debido a los estrictos objetivos de déficit fiscal. ${ }^{158}$ La disminución del presupuesto de salud incluyó una reducción del 70 \% en el programa nacional de emergencia de Chad y resultó en una financiación inadecuada de los hospitales y una "reducción de la prestación de servicios de salud y escasez de medicamentos". ${ }^{159}$ Además, al contribuir a la desregulación del mercado de un sector, el ajuste estructural

\footnotetext{
154 Id.

155 Id.

156 Id. (se encontró que "Ios objetivos prioritarios de gasto se observaron solo alrededor de la mitad del tiempo, aunque casi siempre se cumplieron las condiciones de déficit fiscal").

157 Ver Informe del Experto Independiente en Deuda y Derechos Humanos sobre la mision a Túnez, supra nota 147.

158 Brunswijck, supra nota 72.

159 Id.
} 
puede disminuir la accesibilidad y la calidad de los servicios prestados. ${ }^{160}$

Un último ejemplo merece atención. Como se describió anteriormente, la austeridad tiene un efecto particularmente severo sobre los derechos humanos de quienes viven en situaciones de vulnerabilidad. ${ }^{161}$ En este sentido, las reformas tributarias regresivas que resulten en un cambio de impuestos directos a indirectos pueden tener consecuencias significativas para los hogares de bajos ingresos. ${ }^{162}$ En 2017, sin embargo, se introdujo un aumento significativo en el impuesto al valor agregado en Colombia ${ }^{163}$ y en Costa Rica $^{164}$, siguiendo el consejo del FMI. En un informe sobre una visita a Sri Lanka en 2018, se expresó también preocupación por el aumento significativo del impuesto al valor agregado, dado que los más pobres suelen ser los más afectados por esos impuestos. ${ }^{165}$

Aunque se cree que las medidas de austeridad son temporales, sus efectos duran mucho más allá del período de su aplicación efectiva. Las experiencias de los programas de ajuste estructural en varias regiones -incluyendo el sudeste de Asia, América Latina y África subsahariana hace algunas décadasindican que puede llevar hasta veinte años recuperarse de los impactos de las medidas de ajuste en los derechos humanos. ${ }^{166}$

160 También se observaron en muchos países en 2017 y 2018 "paros del personal de salud que exigen mejoras en los salarios, las condiciones de trabajo y el equipo durante el período del programa del FMI". Id.

161 Ver supra nota 152 y texto adjunto.

162 Informe del Experto Independiente en Deuda y Derechos Humanos sobre el impacto de las reformas económicas y las medidas de austeridad sobre los derechos humanos de las mujeres, supra nota 75.

163 FMI, Columbia: 2017 Article IV Consultation, Staff Report (abril de. 2017).

164 FMI, Costa Rica: 2016 Article IV Consultation, Staff Report (abril de 2016).

165 Informe del Experto Independiente en Deuda y Derechos Humanos sobre la misión a Sri Lanka, 26, U.N. Doc. A/HRC/40/57/Add.2 (7 de enero de 2019).

166 Teresa Cavero y Krisnah Poinasamy, Oxfam, "A Cautionary Tale: The True Cost of Austerity and Inequality in Europe", 17 (2013). 
La austeridad no solo empeora la desigualdad y la pobreza, sino que lo hace a largo plazo.

\section{Complicidad de las instituciones financieras internacionales}

La Sección IV.A. examinará los argumentos jurídicos sustantivos e internacionales que sustentan la responsabilidad de las IFI por su complicidad. La Sección IV.B. analizará los contraargumentos a esta responsabilidad que emanan de las propias IFI y, a su vez, posibles respuestas a los mismos. Finalmente, la Sección IV.C discutirá las implicaciones jurídicas y concretas que acarrea esta responsabilidad.

\section{A. Argumentos detrás de la responsabilidad por complicidad}

Las organizaciones internacionales son responsables de acciones y omisiones que violen sus propias obligaciones. Este principio de responsabilidad independiente es primordial en todo el Proyecto de Artículos de la Comisión de Derecho Internacional (CDI) sobre la responsabilidad de las organizaciones internacionales. ${ }^{167}$ Las organizaciones internacionales también pueden ser consideradas cómplices en hechos ilícitos cometidos por Estados, y la complicidad con los Estados es uno de los medios más comunes de participar en un hecho internacionalmente ilícito. ${ }^{168} \mathrm{La}$ complicidad es un ámbito de responsabilidad independiente que se deriva del principal hecho ilícito que posibilita, en el sentido de que la organización internacional es responsable de la facilitación del principal hecho ilícito. ${ }^{169}$ En otras palabras, si bien esas organizaciones

\footnotetext{
167 El artículo 3 establece que: "Todo hecho internacionalmente ilícito de una organización internacional entraña la responsabilidad internacional de esa organización". Proyecto de Artículos sobre la responsabilidad de los organismos internacionales, supra nota 24, art. 3.

168 Lanovoy, supra nota 23, 2.

$169 \mathrm{Id}$.
} 
pueden ser consideradas directamente responsables de la comisión de un hecho internacionalmente ilícito, la responsabilidad también puede resultar de la prestación de asistencia técnica o financiera a un Estado que es eminentemente el perpetrador. ${ }^{170}$

La complicidad en tales casos se establece cuando se dan tres elementos principales: (1) la ayuda o asistencia proporcionada por una organización internacional en cuestión es considerada internacionalmente ilícita; ${ }^{171}$ (2) la organización internacional era consciente de este hecho ${ }^{172}$ y; (3) existe un vínculo causal entre los bienes o servicios provistos y el daño causado, siendo el daño en este caso la violación de los derechos humanos. ${ }^{173}$

Una organización internacional es responsable de un hecho ilícito cuando una conducta consistente en un acto u omisión constituye una violación de una obligación internacional de esa organización. ${ }^{174} \mathrm{Si}$ bien es cierto que los estatutos impiden que el Banco Mundial ${ }^{175}$ y, mucho menos explícitamente, el FMI, ${ }^{176}$ hagan consideraciones políticas, es difícil argumentar que la violación de los derechos humanos puede ser parte de los asuntos políticos internos de un país. ${ }^{177}$ En otras palabras, las IFI no

170 Draft Articles on the Responsibility of International Organizations, supra nota 24, art. 14. 171 Id.

172 Id.

173 Lanovoy, supra nota 23, 2.

174 Draft Articles on the Responsibility of International Organizations, supra nota 24, art. 4(b).

175 Articles of Agreement of the International Bank for Reconstruction and Development, arts. IV (1), III(5)(b), 27 de diciembre de 1945, 60 Stat. 1440, 2 U.N.T.S. 134; Ver también 3 World Bank Legal Rev., International Financial Institutions and Global Legal Governance 59 (Hassane Cissé et al. eds., 2012) (examina las cláusulas de prohibición política en el Convenio Constitutivo del Banco Mundial).

176 Articles of Agreement of the IMF, arts. I, IV (3)(b), 27 de diciembre de 1945, 60 Stat. 1401, 2 U.N.T.S. 39 (declarando que el FMI "respetará las políticas sociales y políticas internas de los miembros").

177 Ver el art. de la Carta de la ONU. 2 (7) (declarando que "nada de lo contenido en la presente Carta autorizará a las Naciones Unidas a intervenir en asuntos que son esencialmente 
pueden simplemente ignorar los resultados nocivos para los derechos humanos de las políticas que fomentan sobre la base de que estos impactos constituyen asuntos políticos internos sobre los que no tienen autoridad. Refiriéndose al FMI, el Relator Especial Giorgio Gaja de la Comisión de Derecho Internacional sostuvo que no se puede decir "que una organización está libre de responsabilidad internacional si actúa de conformidad con su instrumento constitutivo". ${ }^{178}$ Además, aunque varias IFI establecen el principio de neutralidad en sus estatutos de gobierno, absteniéndose de "hacer consideraciones políticas", estas instituciones violan habitualmente este principio al pasarlo por alto o reinterpretarlo artificialmente para instituir políticas de ajuste estructural. ${ }^{179}$

¿Cuáles son las obligaciones internacionales relevantes que se deben considerar al momento de otorgar un préstamo multilateral? ${ }^{180}$ Se ha argumentado que las convenciones internacionales de derechos humanos, como el Pacto Internacional de Derechos Económicos, Sociales y Culturales (PIDESC), solo vinculan a los Estados partes, mientras que las operaciones de las

de la jurisdicción interna de cualquier Estado"); ver también John Ciorciari, "The Lawful Scope of Human Rights Criteria in World Bank Credit Decisions: An Interpretive Analysis of the IBRD and IDA Articles of Agreement", 33 Cornell Int'I L. J. 331, 357 (2000) (resumiendo la evidencia de que el derecho internacional define estrictamente los "asuntos políticos" de un país como asuntos dentro de su jurisdicción soberana, y afirmando que los asuntos de derechos humanos están fuera de su jurisdicción).

178 Giorgio Gaja (Special Rapporteur), Seventh Rep. on Responsibility of International Organizations, 20, U.N. Doc. A/CN.4/610 (27 de marzo de 2009).

179 Ver Alexander E. Kentikelenis \& Sarah Babb, "The Making of Neoliberal Globalization: Norm Substitution and the Politics of Clandestine Institutional Change", 124 Am. J. Socio., 1720, 1731-38 (2019) (dando cuenta de cómo el FMI transformó su promoción de la "condicionalidad del ajuste estructural" al pasar por alto los procedimientos formales para enmendar el principio de neutralidad en su estatuto y, en cambio, atravesar un proceso de "sustitución de normas").

180 El conjunto de obligaciones de derechos humanos pertinentes en el contexto de las políticas de austeridad ha evolucionado durante las últimas cuatro décadas. Ver Matthias Goldmann, "Contesting Austerity: Genealogies of Human Rights Discourse", (Max Planck Inst., Rsch. Paper No. 9, 2020) (rastreando la "genealogía" de los paradigmas de los derechos humanos en relación con las visiones de austeridad en las décadas desde la década de 1970). 
instituciones financieras internacionales se rigen únicamente por sus propios Artículos de Acuerdo. ${ }^{181}$

Sin embargo, el FMI y el Banco Mundial son agencias especializadas de las Naciones Unidas ${ }^{182} \mathrm{y}$, en consecuencia, deben actuar de conformidad con la Carta de las Naciones Unidas. Más importante aún, como organizaciones internacionales están claramente sujetas al derecho internacional y, por lo tanto, no deben violar el derecho internacional consuetudinario ${ }^{183}$ ni los principios generales del derecho internacional. ${ }^{184}$ En el caso de la responsabilidad por complicidad, estos principios, incluidos, entre otros, los derechos económicos, sociales y culturales encuentran fundamento jurídico en una larga y robusta lista de instrumentos internacionales, casos en el derecho internacional consuetudinario, la jurisprudencia tribunales internacionales y nacionales, y las legislaciones nacionales. ${ }^{185}$ Las IFI no están exentas de la obligación de no violar ni ser cómplices de la

181 François Gianviti, "Economic, Social, and Cultural Rights and the International Monetary Fund", en IMF, Current Developments in Monetary and Financial Law, 3, 29-30 (2005) (examinando en qué medida el FMI puede contribuir a los objetivos del PIDESC en virtud del Convenio Constitutivo del FMI).

182 Agreement Between the United Nations and the International Monetary Fund, 15 de abril de 194816 U.N.T.S. 328; Agreement Between the United Nations and the International Bank for Reconstruction and Development, 15 de abril, 1948, 16 U.N.T.S. 346; G.A. Res. A/RES/ 1594(XV), Agreement on the Relationship Between the United Nations and the International Development Association (27 de marzo de 1961).

183 Interpretation of the Agreement of 25 March 1951 Between the WHO and Egypt, Advisory Opinion, 1980I.C.J.73,37 (20 de diciembre); Giorgio Gaja(Special Rapporteur), FirstRep. on Responsibility of International Organizations, art. 3(1), U.N. Doc. A/CN.4/532 (26 de marzo de 2003) ("Todo hecho internacionalmente ilícito de una organización internacional entraña la responsabilidad internacional de la organización internacional") Giorgio Gaja (Special Rapporteur), Third Rep. on Responsibility of International Organizations, art. 8, U.N. Doc. A/CN.4/553 (13 de mayo de 2005) (“Existe una violación de una obligación internacional por parte de una organización internacional cuando un acto de esa organización internacional no se ajusta a lo que esa obligación le exige, independientemente de su origen y carácter." (énfasis agregado)). 184 Ver Willem van Genugten, The World Bank Group, the IMF and Human Rights: A Contextualised Way Forward 14-17 (2015).

185 Ver Andrew Clapham, Human Rights Obligations of Non-State Actors, 21 (Gráinne de Búrca et al. eds., 2006). 
violación de las normas generales del derecho de los derechos humanos. ${ }^{186}$ El PIDESC enfatiza la obligación de la comunidad internacional de cooperar hacia la realización de los derechos económicos, sociales y culturales. ${ }^{187}$

El Comité de Derechos Económicos, Sociales y Culturales, el organismo encargado de interpretar con autoridad el PIDESC, ha destacado que las IFI y otras organizaciones internacionales están "obligadas por las obligaciones que les incumben en virtud de las normas generales del derecho internacional, en virtud de su constituciones o en virtud de acuerdos internacionales de los que son parte". ${ }^{188}$

El Comité de Derechos Económicos, Sociales y Culturales ha especificado además que tales organizaciones "están por tanto obligadas a respetar los derechos humanos, enumerados en particular en la Declaración Universal de Derechos Humanos, que forman parte del derecho internacional consuetudinario o de los principios generales del derecho". ${ }^{189}$

Es importante señalar que los Estados no pueden simplemente desplegar IFI para eludir sus claras obligaciones en virtud del derecho internacional, incluidas las obligaciones que emanan del PIDESC, mediante la delegación de competencias en una organización internacional o IFI para que actúe en su nombre. ${ }^{190}$ Según el Principio Rector 15.3, "la delegación no

\footnotetext{
186 Christian Tomuschat, International Law: Ensuring the Survival of Mankind on the Eve of a New Century: General Course on Public Internationa Law, 138-39 (1999).

187 International Covenant on Economic, Social and Cultural Rights, opened for signature 16 de diciembre de 1966, 993 U.N.T.S. 3, art. 2 1) (comenzó a regir el 3 de enero de 1976).

188 Public Debt, Austerity Measures, \& ICESCR, supra nota 58, 7 (citando la interpretación del Acuerdo del 25 de marzo de 1951 entre OMS y Egipto, Opinión Consultiva, 1980 I.C.J. Rep. 73, 37 (diciembre 20).

189 Id.

190 Ian Brownlie, "State Responsibility: The Problem of Delegation", en Völkerrecht zwischen normativem Anspruch und politischer Realität 299, 300 (Ginther et al. eds. 1994); Draft Articles on the Responsibility of International Organizations, supra nota 24, art. 7 (“La conducta de un órgano de un Estado o de un órgano o agente de una organización internacional que se
} 
puede utilizarse como excusa para incumplir las obligaciones de derechos humanos, en abnegación del carácter extraterritorial de estas obligaciones". ${ }^{191}$ Según el CESCR, esta política alienta a los Estados, ellos mismos miembros de organizaciones internacionales, incluidas las IFI como el FMI, "a garantizar que las políticas de estas organizaciones estén en conformidad con las obligaciones de los Estados partes en virtud del Pacto". ${ }^{192}$

Los Estados deben poder utilizar su espacio legal y político para diseñar e implementar programas económicos en línea con sus obligaciones de derechos humanos. ${ }^{193}$ Cuando las instituciones financieras internacionales ejercen una influencia externa indebida sobre los Estados, hacerlo puede equivaler a complicidad en los daños resultantes. ${ }^{194}$ El término "influencia externa indebida" en el contexto económico se entiende que significa la intervención directa o indirecta en los asuntos económicos de un Estado "mediante el uso de medidas económicas y/o políticas que buscan influir [en el Estado] para que adopte determinadas políticas económicas u obtener de ellos ventajas de cualquier

ponga a disposición de otra organización internacional se considerará, en virtud del derecho internacional, un acto de esta última organización si la organización ejerce un control efectivo sobre esa conducta").

191 Principios Rectores, supra nota 3, princ. 15.3. “Los Estados no pueden eludir la responsabilidad de las acciones o el ejercicio de funciones que han delegado a instituciones internacionales o partes privadas (reintegro de finanzas y privatización)". Id.

192 Comm. on Econ., Soc., \& Cultural Rts., Concluding Observations on the Third Periodic Report of Ireland, 35, U.N. Doc. E/C.12/IRL/CO/3 (julio 8, 2015).

193 Ver Principios Rectores, supra nota 3, princ. 4 (que prohíbe el uso de crisis económicas "para justificar una reducción del espacio político y fiscal necesario en los niveles de gobierno local y subnacional para garantizar la protección de los derechos humanos"); G.A. Res. 70/1, U.N. Doc A/RES/70/1, 17.15 (25 de septiembre de 2015) (en el que se pide el reconocimiento del "espacio de políticas y liderazgo de cada país para establecer e implementar políticas para la erradicación de la pobreza y el desarrollo sostenible"); G.A. Res. 69/313, U.N. Doc A/RES/69/313, 9 (25 de julio de 2015) (reafirmando que "cada país tiene la responsabilidad principal de su propio desarrollo económico y social"); GA Res. 2625 (XXV), en 121 (24 de octubre de 1970) (reconociendo la "igualdad soberana" y las responsabilidades iguales compartidas por diferentes naciones).

194 Draft Articles on the Responsibility of International Organizations, supra nota 24, art. 15. 
tipo que socaven su capacidad para respetar, proteger y cumplir sus obligaciones en materia de derechos humanos". ${ }^{195}$ Tales medidas económicas pueden comprender no sólo las condicionalidades directamente vinculadas a los programas de asistencia financiera, sino también las condicionalidades implícitas que las instituciones internacionales o regionales hayan presionado informalmente a los países para que las adopten. ${ }^{196}$

\section{B. Análisis de los contraargumentos de las IFI}

Durante la discusión y codificación del Proyecto de Artículos sobre la responsabilidad de las organizaciones internacionales, algunas organizaciones internacionales que proporcionan financiamiento objetaron el contenido de la complicidad y su vínculo con el principal hecho ilícito, que podría establecerse mediante la prestación de asistencia financiera. ${ }^{197}$ En particular, el Banco Mundial destacó con respecto a la aplicación de la disposición sobre ayuda y asistencia a las organizaciones internacionales que "si no se limita estrictamente a su alcance adecuado, esta disposición es preocupante y puede crear un peligroso efecto paralizador para cualquier institución financiera internacional que brinde asistencia económica a prestatarios y beneficiarios elegibles". ${ }^{198}$

En la misma línea, el FMI expresó su preocupación por la interpretación del artículo 16 del Proyecto de Artículos, que asimilaba la ayuda o asistencia a la facilitación o provisión de financiamiento que sería fundamental o que haya contribuido significativamente al acto en cuestión. ${ }^{199}$ El organismo esperaba que, "dada la naturaleza fungible de la asistencia financiera", cualquier

\footnotetext{
195 Principios Rectores, supra nota 3, princ. 14.1

196 Id.

197 Int'I Law Comm'n, Responsibilities of International Organizations, Comments and Observations Received from International Organizations, U.N. Doc A/CN.4/637, 27 (2011).

$198 \mathrm{Id}$

199 Draft Articles on the Responsibility of International Organizations, supra nota 24, art. 16.
} 
responsabilidad en que pudiera incurrir una organización internacional en este escenario se limitaría al ámbito en el que habría brindado "asistencia (...) destinada a la conducta ilícita". ${ }^{200}$ Refiriéndose a esa asistencia "indebida" selectiva, el FMI subrayó que:

Esto debe distinguirse de ayuda y asistencia, ya que esas palabras se usan coloquialmente, que las organizaciones internacionales proporcionan regularmente a sus miembros. Por ejemplo, el FMI se estableció, entre otras cosas, para brindar asistencia financiera a sus miembros a fin de ayudarlos a resolver sus problemas de balanza de pagos. De conformidad con su estatuto, el FMI proporciona periódicamente dicha asistencia financiera. Dicho esto, un miembro que reciba asistencia financiera del FMI aún puede participar en una conducta ilícita. Ni el propio FMI, ni la prestación de asistencia financiera por parte del FMI, pueden impedir tal conducta o contribuir de manera significativa a ella. ${ }^{201}$

Por lo tanto, el FMI expresó su preocupación de que pudiera ser considerado responsable por la "conducta ilícita" de un Estado sobre el que no tenía poder coercitivo, en el sentido de que "un miembro siempre tiene la opción efectiva de no seguir las condiciones en las que el FMI otorga asistencia”. ${ }^{202}$ El FMI continuó destacando que:

El FMI no puede contribuir de manera significativa a tal conducta porque el financiamiento del FMI no está dirigido a una conducta particular; se proporciona para apoyar el programa económico de un miembro que aborda sus problemas de balanza de pagos. Los recursos financieros utilizados por el miembro para participar en una conducta particular pueden obtenerse, y generalmente se obtienen, de una variedad de fuentes: contribuyentes nacionales,

\footnotetext{
200 Int'I Law Comm'n, Responsibilities of International Organizations, Comments and Observations Received from International Organizations, U.N. Doc A/CN.4/582, 10 (1 de mayo de 2007).

201 Id.

202 Id.
} 
acreedores nacionales e internacionales y donantes internacionales. El carácter fungible de los recursos financieros también significa que la asistencia financiera del FMI nunca puede ser esencial, o contribuir significativamente, a una conducta ilícita particular de un Estado miembro. ${ }^{203}$

Estos argumentos se pueden dividir en cuatro elementos. ${ }^{204}$ En primer lugar, el Banco Mundial advierte que la responsabilidad por la complicidad aplicada a las IFI podría tener un "efecto paralizador" y limitar las provisiones financieras a los prestatarios y receptores. ${ }^{205}$ Aparte del hecho de que esta afirmación tendría que ser probada empíricamente, esto no es necesariamente algo de lo que preocuparse si la asistencia financiera no proporcionada hubiera tenido un impacto adverso sobre los derechos humanos.

En segundo lugar, como cuestión de principio, el FMI sostiene que no puede ser responsable de lo que pueda provocar su financiación, ya que los Estados prestatarios siempre tienen la opción de no seguir las condiciones en las que se otorgan los préstamos. ${ }^{206}$ Este argumento es problemático. Por un lado, los Estados que atraviesan temporalmente turbulencias financieras y pierden el acceso a otras fuentes de fondos suelen recurrir a las IFI, normalmente el FMI. ${ }^{207}$ Como resultado, el FMI ve mejorado su poder de negociación con respecto al prestatario, de modo que el prestatario no es completamente libre de elegir sus propias políticas económicas. ${ }^{208}$ Como tal,

\footnotetext{
203 Id.

204 Lanovoy, supra nota 23.

205 Supra nota 198 y texto adjunto.

206 Supra notas 200-202 y textos adjuntos.

207 Ver supra Sección I.A.

208 Giorgio Gaja (Special Rapporteur), Third Rep. on Responsibility of International Organizations, 28, U.N. Doc. A/CN.4/553 (13 de mayo de 2005) (donde se indica que "[un] ejemplo hipotético de coacción sería el de una organización financiera internacional que imponga condiciones estrictas para un préstamo esencial y, por lo tanto, coaccione al Estado receptor a infringir obligaciones para con otro Estado o determinadas personas").
} 
"los prestamistas en realidad tienen una mayor responsabilidad con respecto a los impactos sobre los derechos humanos de sus préstamos y las condiciones que se les imponen". ${ }^{209}$ Por otro lado, incluso cuando el Estado prestatario pueda decidir libremente qué camino económico seguir, si la IFI conoce o ignora intencionalmente el hecho ilícito financiado, debería asumir la responsabilidad por esta asistencia, siempre que se cumpla con el requisisito de la causalidad. ${ }^{210}$

En tercer lugar, el financiamiento proporcionado por el FMI es de naturaleza genérica, ya que no está diseñado para financiar ningún proyecto en particular, y existen necesariamente varias fuentes financieras concurrentes que los Estados prestatarios podrían utilizar para facilitar la implementación de políticas económicas regresivas. ${ }^{211}$ Pero una multiplicidad de causas no es suficiente para excluir la responsabilidad; solo requiere la adecuada asignación de responsabilidades entre los/as culpables. La asignación de responsabilidades debe hacerse de acuerdo con el comportamiento real de cada agente y sus consecuencias. $^{212}$ Un principio propuesto de responsabilidad solidaria haría responsable a una de las partes y les permitiría recuperar parcialmente las pérdidas de los demás, lo que permitiría equilibrar los diversos intereses de las partes perjudicadas y responsables. ${ }^{213}$

Y cuarto, el FMI argumenta que la fungibilidad de la asistencia financiera del FMI le impediría contribuir significativamente a la perpetración de un hecho internacionalmente

\footnotetext{
209 Principios Rectores, supra nota 3, princ. 14.

210 Draft Articles on the Responsibility of International Organizations, supra nota 24, art. 14

211 Como la asistencia financiera de otros acreedores y donantes multilaterales, bilaterales y privados.

212 Roger P. Alford, “Apportioning Responsibility Among Joint Tortfeasors for International Law Violations", 38 Pepp. L. Rev. 233, 237 (2011).

213 Christiane Ahlborn, "To Share or Not to Share? The Allocation of Responsibility Between International Organizations and Their Member States", 88 (3-4), Die Friedens-Warte D 45, 47 (2013).
} 
ilícito. ${ }^{214}$ Sin embargo, la fungibilidad del dinero no significa que los préstamos no contribuyan nunca a la comisión de violaciones de derechos humanos. ${ }^{215}$ No equivale a neutralidad. Como se señala en el contexto de complicidad financiera por parte del Estado: "Si bien es ciertamente difícil establecer cualquier forma de causalidad específica entre la concesión de una determinada cantidad de dinero y un hecho internacionalmente ilícito específico, proporcionaría a los Estados una laguna muy tentadora si pudieran evitar la responsabilidad de complicidad simplemente recurriendo al flujo de efectivo en lugar de proporcionar ayuda material en el sentido tradicional". ${ }^{216}$

Es importante señalar que la responsabilidad en este contexto no se trata solo de la provisión directa de dinero por parte de las IFI, sino también del llamado "efecto catalizador" de dichos préstamos, que envían una señal a los mercados internacionales. ${ }^{217}$ Esto afecta tanto a las decisiones de los/as inversores/as como a los costos de endeudamiento de los Estados, los cuales a menudo tienen un impacto mucho mayor en las finanzas públicas que las modestas cantidades que proporciona el FMI.

Nada en el Proyecto de Artículos sobre la responsabilidad de las organizaciones internacionales indica un apoyo al argumento del FMI de que las contribuciones deben ser esenciales para generar responsabilidad por sus impactos. Este requisito podría aplicarse al financiamiento de proyectos más discretos,

\footnotetext{
214 Supra nota 203 y texto adjunto.

215 Sabine Michalowski \& Juan Pablo Bohoslavsky, "lus Cogens, Transitional Justice and Other Trends of the Debate on Odious Debts: A Response to the World Bank Discussion Paper on Odious Debts", 48 Columbia J. Transnat'I L. 59, 74-80 (2009) (examina la evolución de los precedentes judiciales en relación con los préstamos monetarios fungibles que se utilizan para financiar las violaciones de los derechos humanos de los Estados, como el apartheid).

216 Helmut Aust, "The Concept of Complicity in Article 16 ASR", en Complicity and the Law of State Responsibility, 192, 199 (2011).

217 Thomas H. Stubbs et al., "Catalyzing Aid? The IMF and Donor Behaviour in Aid Allocation", 78 World Dev. 511, 524 (2016).
} 
pero no a la asistencia financiera masiva para respaldar programas macroeconómicos. Un gran debate legal y académico sobre este tema ha florecido en los últimos años. ${ }^{218}$ La Comisión de Derecho Internacional ha subrayado que "el Estado que presta asistencia solo será responsable en la medida en que su propia conducta haya causado o contribuido al hecho internacionalmente ilícito". ${ }^{219}$ Por lo tanto, "la pregunta clave que debe plantearse es si una determinada acción u omisión facilitó que otro Estado u organización internacional" incurriera en la conducta ilícita. ${ }^{20}$ Por supuesto, debe haber una "conexión muy estrecha entre la autorización o recomendación [hecha por una IFI] y el acto pertinente del Estado miembro". ${ }^{221}$

Existe un vínculo causal directo entre la austeridad y las violaciones de los derechos humanos, y las últimas son consecuencias previsibles de las primeras. ${ }^{222}$ Por lo tanto, si el asesoramiento técnico, la vigilancia o el apoyo financiero otorgado por una IFI a un Estado prestatario facilitó o promovió la implementación de medidas económicas regresivas inadmisibles que impactaron negativa e injustificadamente en el disfrute de los derechos humanos, el prestamista debería asumir la carga de demostrar que la financiación se proveyó sin conocimiento de las circunstancias del principal hecho ilícito. ${ }^{223}$ Este cambio en

\footnotetext{
218 Ver Sheldon Leader, "Project Finance and Human Rights", en Making Sovereign Financing and Human Rights Work, supra nota 46, 199, 202-11.

219 Draft Articles on Responsibility of States for Internationally Wrongful Acts, with Commentaries, [2001] 2 Y.B. Int'I L. Comm'n 30, 66, U.N. Doc. A/CN.4/SER.A/2001/Add.1.

220 Lanovoy, supra nota 23, 185.

221 Int'I Law Comm'n, Rep. on the Work of its Fifty-Seventh Session, U.N. Doc., A/C.6/60/ SR.11, 11, (2005); Ver también, FMI, "The IMF and Social Protection", 25 (5 de julio de 2017) (en el que se evalúa si "los programas respaldados por el FMI [hicieron] daño inadvertidamente a la protección social", y se concluye que en la mayoría de los casos analizados, "las autoridades del país eligieron retener ciertos subsidios, como los que se aplican a los productos combustibles comúnmente utilizados por los pobres... y el personal del FMI, reconociendo sus beneficios pragmáticos, no se opuso").

222 Ver supra Partes I-II.

223 Lanovoy, supra nota 23.
} 
la carga de la prueba resulta legítimo dado que las víctimas de violaciones económicas y sociales de derechos humanos pueden no tener acceso a la evidencia relevante de las instituciones financieras internacionales o de los Estados, ${ }^{224}$ como ha sido reconocido por el sistema interamericano de derechos humanos en sus decisiones que establecen la responsabilidad del Estado por desapariciones forzadas. ${ }^{225}$

Una forma eficaz de demostrar esta falta de conocimiento es demostrando que se llevó a cabo una evaluación de impacto sobre los derechos humanos y que se tomaron medidas para evitar consecuencias adversas sobre los derechos humanos de manera oportuna. ${ }^{226}$ Esto es particularmente crucial en el contexto de la pandemia del COVID-19. ${ }^{227}$ Las medidas que darían lugar a retrocesos en cuanto a la realización de los derechos económicos, sociales y culturales son admisibles solo si los Estados pueden demostrar que esas medidas regresivas se ajustan a una serie de criterios, ${ }^{228}$ como se describe en los Principios Rectores. ${ }^{229}$

224 Ver Ahmadou Sadio Diallo (Republic of Guinea v. Democratic Republic of the Congo), Judgment, 2010 I.C.J. 639, 661, 55 (30 de noviembre) (sancionando un cambio similar de la carga de la prueba dado que, a diferencia de una presunta víctima de abusos gubernamentales, "[una] autoridad pública generalmente puede demostrar que ha seguido los procedimientos apropiados y aplicado las garantías requeridas por la ley, si tal fue el caso, mediante la presentación de prueba documental de las acciones realizadas").

225 Velásquez Rodríguez V. Honduras, Merits, Judgement, Inter-Am. Ct. H.R, 122-39 (29 de julio de 1998).

226 Principios Rectores, supra nota 3. Princ.3

227 "U.N. Checklist for Human Rights and COVID-19", supra nota 9.

228 Ver "Public Debt, Austerity Measures, \& ICESCR", supra nota 58 (donde se explica que "[s] i la adopción de medidas regresivas es inevitable, tales medidas deben ser necesarias y proporcionadas, en el sentido de que la adopción de cualquier otra política o no actuar sería más perjudicial para los derechos económicos, sociales y culturales", y afirmando que tales medidas deben "permanecer en vigor solo en la medida en que sean necesarias... no dar lugar a discriminación... mitigar las desigualdades que pueden aumentar en tiempos de crisis y garantizar que los derechos de las personas y grupos desfavorecidos y marginados no se vean afectados de manera desproporcionada" y, sobre todo, no deben interferir con el núcleo fundamental de los derechos humanos protegidos por el PIDESC).

229 Ver Principios Rectores, supra nota 3. Princ. 10. 
Como tal, el continuo desdén de las IFI para llevar a cabo evaluaciones de impacto sobre los derechos humanos en el diseño, imposición e implementación de los acuerdos de préstamo de los países evidencia una obstinada insistencia en ignorar o despreciar los efectos perjudiciales de las medidas de austeridad sobre los derechos humanos. ${ }^{230}$

\section{Consecuencias de la responsabilidad}

Ser responsable por complicidad acarrea una serie de consecuencias jurídicas, ${ }^{231}$ que incluyen cuatro obligaciones principales: prevención, cese, no repetición y la reparación. ${ }^{232}$

Si el hecho internacionalmente ilícito es de carácter continuo, como lo son la mayoría de las reformas económicas y sus impactos, la obligación de cesación tiene, por tanto, una relevancia específica. Las garantías de no repetición están vinculadas a la prevención que, en el caso de las IFI, deben incluir el uso sistemático y obligatorio de evaluaciones de impacto ex ante sobre los derechos humanos. ${ }^{233}$ En términos de reparación, que incluye restitución, compensación y satisfacción, ${ }^{234}$ los complejos

230 Ver Principios Rectores, supra nota 3, principios. 17-18 (afirmando la importancia de las evaluaciones de impacto sobre los derechos humanos); ver también Nolan \& Bohoslavsky, supra nota 2, en 1248-1250 (donde se discute el "margen y el socavamiento de los derechos humanos en el diseño y la implementación de la reforma de la política económica" y señalando la resistencia del FMI a emprender evaluaciones de impacto sobre los derechos humanos, tal como fuera lo expresara en una carta enviada en relación con los Principios Rectores: "el FMI no puede utilizar sus poderes (...) para involucrarse directamente en la promoción de los derechos humanos").

231 Ver Jam v. Int'l Fin. Corp., 139 S. Ct. 759 (2019) (sostiene que las organizaciones internacionales gozan de la misma inmunidad a la que tienen derecho actualmente los soberanos extranjeros; es decir, no se les concede inmunidad absoluta).

\section{Lanovoy, supra nota 23.}

233 Principios Rectores, supra nota 3, princ. 18; Nolan \& Bohoslavsky, supra nota 2, en 1253 (donde se indica que las evaluaciones de impacto sobre los derechos humanos "deberían ser un elemento obligatorio en el diseño de todos los programas de reforma y ajuste económicos, incluso en el contexto de la gestión de la deuda y las actividades de asistencia financiera").

234 Lanovoym, supra nota 23, en 269; ver también Draft Articles on the Responsibility of International Organizations, supra nota 24, arts. 35-37 (donde se brindan descripciones de las tres formas de reparación). 
efectos distributivos, acumulativos y de corto y largo plazo de las reformas económicas plantean un gran desafío; las evaluaciones ex post del impacto en los derechos humanos son, por tanto, de suma importancia para desandar y remediar las medidas regresivas y sus efectos.

Otra implicación importante de la responsabilidad de las IFI por complicidad es su obligación de absorver algunas pérdidas financieras en caso de incumplimiento del Estado, ${ }^{235}$ teniendo en cuenta su nivel de imprudencia hacia el deudor soberano, su población y los demás acreedores. ${ }^{236}$

\section{Conclusiones y recomendaciones para la discusión}

Como se analiza en este documento y en una serie de informes a la Asamblea General de la ONU y al Consejo de Derechos Humanos, las medidas de austeridad suelen tener como resultado una serie de impactos negativos sobre los derechos humanos. ${ }^{237}$ Por lo tanto, existe una base legal sólida para sostener que existe una inconsistencia prima facie entre la implementación de políticas de austeridad en tiempos de recesión y la obligación de proteger el disfrute de los derechos humanos. ${ }^{238}$

235 Kunibert Raffer, "Preferred or Not Preferred: Thoughts on Priority Structures of Creditors" (Oct. 16. 2009) (inédito).

236 Juan Pablo Bohoslavsky, "Lending and Sovereign Insolvency: A Fair and Efficient Criterion to Distribute Losses Among Creditors", 2 Goettingen J. Int'I L. 387, 396-98 (2010) (donde se postula que "las normas concursales nacionales han intentado desalentar los préstamos abusivos" obligando a los acreedores que otorgan dichos préstamos a "percibir menos dinero en los procedimientos de insolvencia").

237 Informe del Experto Independiente en Deuda y Derechos Humanos, "Development of Guiding Principles for Assessing the Human Rights Impact of Economic Reform Policies", 4-7, U.N. Doc. A/HRC/37/54 (17 de diciembre de 2017); Informe supra nota 75, 24-56 (donde se detalla el impacto negativo de la austeridad en los derechos humanos de las mujeres); también el informe de la misión a Grecia, supra nota 44, 55-74 (detallando los impactos negativos de las medidas de austeridad en los derechos humanos en ese país).

238 Principios Rectores, supra nota 3, princ. 10; ver también Comm. en Econ., Soc. \& Derechos Culturales, Rep. Sobre la quinta sesión, U.N. Doc. E / 1991/23, págs. 85 a 86 (1991) (donde se identifica una obligación básica mínima [de parte de los Estados partes en el 
No hay evidencia de que la llamada austeridad expansionista exista siquiera desde un punto de vista económico. Es mucho más claro que los programas de ajuste estructural están vinculados a la disminución del crecimiento económico, el empleo, la sostenibilidad de la deuda y la igualdad. ${ }^{239}$ No es sorprendente que la combinación de recesiones económicas y giros contractivos en la política fiscal hayan afectado a una amplia gama de derechos humanos, en particular los derechos de quienes se encuentran en situaciones más vulnerables. Es obvio que las amenazas al gasto público, cuando y donde más se necesita, crean un alto riesgo de violaciones de derechos humanos. ${ }^{240}$

No es que todas las políticas de reforma económica que respondan a las crisis económicas sean intrínsecamente contrarias a la protección de los derechos humanos ${ }^{241}$ pero la austeridad carece de una justificación teórica y empírica seria desde una perspectiva de derechos humanos. Dados los antecedentes negativos de las políticas de austeridad en materia de derechos humanos, es sorprendente que las reformas económicas y las medidas adoptadas por los Estados para implementar las condicionalidades basadas en la austeridad rara vez vayan acompañadas de evaluaciones ex ante del impacto en los derechos humanos. $^{242} \mathrm{Si}$ bien los Estados siguen siendo los principales garantes de deberes en este ámbito, ${ }^{243}$ las IFI también pueden

PIDESC] de asegurar la satisfacción de, como mínimo, los niveles mínimos esenciales de derechos económicos, sociales y culturales, y el razonamiento de que "un Estado parte en el que un número significativo de personas se ve privado de alimentos esenciales, atención médica, vivienda y servicios básicos, o de las formas más básicas de educación está, prima facie, incumpliendo sus obligaciones en virtud del [PIDESC]").

239 Supra Sección II.A

240 Supra Parte III.

241 Principios Rectores, supra nota 3. Princ. 1

242 U.N. Secretary-General, Estimates in Respect of Special Political Missions, Good Offices and Other Political Initiatives Authorized by the General Assembly and/or the Security Council, 63, U.N. Doc. A/71/365 (17 de octubre de 2016).

243 PIDESC, supra nota 187, art. 2; Principios Rectores, supra nota 3, en princ. 2 (“Las decisiones económicas que tomen los Estados, ya sea que actúen solos o como miembros 
ser consideradas responsables por su complicidad al prescribir políticas con claros impactos potenciales sobre los derechos humanos y/o contribuir a violaciones de los derechos humanos en este contexto.

El hecho de que las IFI $^{244}$ o los Estados ${ }^{245}$ no realicen ni requieran evaluaciones de impacto sobre los derechos humanos con regularidad es incompatible con su práctica (aunque imperfecta) de realizar evaluaciones de impacto ambiental y social cuando se trata de financiación de proyectos. ${ }^{246} \mathrm{Si}$ se les puede responsabilizar por el daño evitable causado a los afectados por una represa financiada, ¿por qué no deberían ser responsables del daño evitable a los derechos humanos producido por las reformas económicas regresivas?

En este contexto, el presente artículo desarrolla el argumento de que, de acuerdo con los estándares del derecho internacional, las IFI pueden ser consideradas responsables de la complicidad con reformas económicas que violan los derechos humanos. El vínculo causal entre la asistencia brindada (préstamos, vigilancia y asistencia técnica, y condicionalidades adjuntas) en la comisión de un hecho ilícito (complicidad) y el daño causado (violaciones de derechos humanos) es evidente y está bien documentado. ${ }^{247} \mathrm{El}$ conocimiento de la naturaleza ilícita del acto puede presumirse si, incluso cuando se impulsan reformas económicas que normalmente conducen a violaciones de derechos humanos, no se realiza ex ante una evaluación

de instituciones financieras internacionales, deben cumplir con sus obligaciones internacionales en materia de derechos humanos en todo momento, incluso en tiempos de crisis económica").

244 Nolan \& Bohoslavsky, supra nota 2.

245 Id.

246 Ver WBG, Environmental and Social Framework (2018) (donde se discute cómo el uso de evaluaciones de impacto ambiental y social permite al Banco Mundial y a los prestatarios gestionar mejor los riesgos ambientales y sociales de los proyectos y mejorar los resultados de desarrollo).

247 Supra sección IV.A 
de impacto. La responsabilidad legal por complicidad genera obligaciones en materia de prevención, cese, no repetición y reparación. ${ }^{248}$

Debido a las circunstancias habituales en las que se encuentran los Estados cuando solicitan asistencia a las IFI, los prestamistas suelen imponer condiciones que no necesariamente se negocian con los Estados prestatarios, y sus poblaciones están aún menos involucradas en las consultas, discusiones o negociaciones asociadas. ${ }^{249}$ Además, el alcance de las condicionalidades se ha expandido continuamente durante las últimas décadas. ${ }^{250}$ Todo esto ayuda a comprender el grado de penetración y omnipresencia de las condicionalidades en los asuntos soberanos clave, incluso teniendo en cuenta el rechazo abrumador de las poblaciones respectivas y los objetivos de orientación social de las IFI, de acuerdo con sus propios estatutos. ${ }^{251}$

Las IFI deben aprender de la implementación exitosa de medidas anticíclicas y programas de ajuste que cumplen en gran medida con los derechos humanos, como los de Malasia (1997-1998), que impusieron controles de capital a las salidas a corto plazo, ${ }^{252}$ y en Islandia (2009-2010), que también incluyó controles de capital, el resguardo del sistema de bienestar social de recortes y un fuerte enfoque en la generación y redistribución de ingresos a través de políticas tributarias. ${ }^{253}$

En la década de 1960, la Asamblea General pidió al Banco Mundial y otras instituciones internacionales que se abstuvieran

\footnotetext{
248 Supra sección IV.C

249 Supra sección I.A

250 Supra sección I.B

251 Ver Articles of Agreement of the International Bank for Reconstruction and Development, supra nota 175, art I; Articles of Agreement of the IMF, supra nota 176, art. I (ii).

252 Marion Pircher, "Short-Term Capital Controls and Malaysia's Fast Recovery After the East-Asian Crisis", en Soveriegn Debt Crises: What Have We Learned?, supra nota 48.

253 Juan Pablo Bohoslavsky, "Iceland: A Human Rights-Sensitive Approach to Deal with Financial Crises" en Soveriegn Debt Crises: What Have We Learned? supra nota 48.
} 
de otorgar préstamos a Sudáfrica debido a su pobre historial de derechos humanos. ${ }^{254}$ El Banco Mundial dejó de aprobar préstamos al régimen del apartheid en 1966. ${ }^{255}$ No puede haber ninguna justificación jurídica para que las IFI se abstengan de facilitar las violaciones de los derechos civiles y políticos pero sigan siendo cómplices de la imposición de violaciones de los derechos económicos, sociales y culturales. Las amplias implicaciones adversas para los derechos humanos de las medidas económicas regresivas son ampliamente conocidas, sin embargo, las IFI las promueven y alientan regularmente; este artículo explica cómo esto da lugar a su responsabilidad legal por complicidad.

Junto con algunos esfuerzos para fortalecer las redes de seguridad social por razones humanitarias, las IFI continúan promoviendo la austeridad y otras políticas económicas regresivas incluso en el contexto de la respuesta a la crisis del COVID-19. ${ }^{256}$ Los pre-supuestos macroeconómicos y fiscales, así como las políticas económicas subyacentes detrás de los préstamos de las IFI a los Estados para ayudarlos a superar la recesión económica inducida por el COVID-19, indican claramente que la disciplina fiscal y las opciones favorables al mercado seguirán siendo prioritarias una vez que se comience a superar la emergencia sanitaria mundial. ${ }^{257}$ Esto a pesar de que se ha reconocido que la recuperación económica es una condición previa para la consolidación fiscal, y no al revés. ${ }^{258}$

A la luz de estas observaciones finales, aquí se presentan una serie de recomendaciones institucionales, normativas y de

\footnotetext{
254 Ver Samuel A. Bleicher, "UN v. IBRD: A Dilemma of Functionalism", 24 Int'l Org. 31, 34-41 (1970).

255 Id.

256 Ver supra Introducción.

257 Id.; Nolan \& Bohoslavsky, supra nota 2.

258 UNCTAD, "Trade and Development Report: From Global Pandemic to Prosperity for All: Avoiding Another Lost Decade", 94 (2020).
} 
políticas públicas para su discusión académica. Las recomendaciones fueron parte de un informe discutido con los Estados en la reunión de la Asamblea General el 21 de octubre de 2019. ${ }^{259}$

Así, se recomienda a las instituciones financieras internacionales:

(a) Incluir en sus documentos de políticas un compromiso explícito de respetar todos los derechos humanos, incluidos los derechos laborales, en sus políticas de préstamos, vigilancia y asistencia técnica.

(b) Llevar a cabo evaluaciones independientes, participativas, informadas, transparentes y sensibles al género de las repercusiones en los derechos humanos de las políticas de reforma económica antes y después de determinar ciertas condiciones y, de manera más general, reformas económicas para los prestatarios/receptores estatales, de conformidad con los Principios Rectores: ${ }^{260}$ esta evaluación no debe reemplazar (ni ser reemplazada por) las prácticas existentes con respecto a las evaluaciones de impacto ambiental y social.

(c) Asegurar que los términos de sus transacciones y sus propuestas de políticas de reforma y las condiciones para el apoyo financiero no socaven la capacidad del Estado prestatario/receptor de respetar, proteger y cumplir sus obligaciones de derechos humanos: esto incluye identificar y evitar políticas de reformas económicas que tendrían implicaciones negativas para el disfrute de los derechos humanos, en particular de quienes se encuentran en las situaciones más vulnerables.

(d) Proponer una lista (no exhaustiva) de medidas preventivas y mitigantes, que vaya mucho más allá de las medidas de protección social específicas para garantizar la conformidad de las políticas de reforma económica consideradas con las obligaciones de los Estados en materia de derechos humanos,

\footnotetext{
259 Nolan \& Bohoslavsky, supra nota 2.

260 Principios Rectores, supra nota 3. Princs. 17-20.
} 
y asegurarse de que esos mecanismos proporcionen reparación a aquellos/as directamente afectados/as negativamente por las políticas de las IFI.

(e) Considerar las metas de gasto prioritario en derechos humanos como condiciones vinculantes y exigibles, con consecuencias financieras concretas si no se cumplen. ${ }^{261}$

(f) Añadir una dimensión de derechos humanos al análisis de sostenibilidad de la deuda y garantizar que los resultados de las evaluaciones de impacto desempeñen sistemáticamente un papel en las reestructuraciones de deuda.

(g) Incluir las conclusiones de las evaluaciones del impacto en los derechos humanos y supervisar su evolución mediante un examen de las IFI y los procesos de presentación de informes ya establecidos.

(h) Participar, como suelen hacer otros acreedores, en negociaciones de alivio de la deuda y reestructuración, con el objetivo de apoyar la liberación del espacio fiscal para salvaguardar la capacidad de los Estados para cumplir con sus obligaciones en materia de derechos humanos: en el caso de IFI cómplices con medidas económicas regresivas, esta obligación es aún más marcada.

También se recomienda que los Estados, como miembros de IFI:

a) Ejerzan sus funciones como miembros de IFI y de diversos directorios, de conformidad con las normas de derechos humanos.

b) Exijan que las IFI cuenten con políticas de derechos humanos y supervisen su aplicación.

c) Impulsen la inclusión de evaluaciones obligatorias ex ante y ex post del impacto en los derechos humanos en los procesos de negociación y métodos oficiales de trabajo.

261 Thomas Stubbs \& Alexander E. Kentikelenis, "Targeted Social Safeguards in the Age of Universal Social Protection: The IMF and Health Systems of Low-Income Countries", 28 Critical Pub. Health 132, 136-37 (2018). 
d) Velen por que se realicen evaluaciones del impacto en los derechos humanos antes de seguir adelante con decisiones y/o recomendaciones que impliquen reformas económicas a nivel de país.

e) Alienten a las IFI que ya cuentan con mecanismos independientes de rendición de cuentas a fortalecerlos, y a las IFI, como el FMI, que aún no cuentan con tales mecanismos, a crearlos, velando por que sean accesibles y ampliamente conocidos.

La importancia de realizar evaluaciones de impacto sobre los derechos humanos antes de implementar políticas económicas es aún mayor ahora en el contexto de la pandemia del COVID-19, ya que las políticas económicas tienen implicaciones epidemiológicas que el diseño y la implementación de políticas deben tomar en consideración. ${ }^{262}$ Este artículo ha demostrado que la desconexión entre los derechos humanos y la política económica puede ayudarnos a comprender por qué aumentan la pobreza y la desigualdad. Ahora, esa misma desconexión pone en riesgo la supervivencia de la humanidad.

262 FMI, "A Long and Difficult Ascent, World Economic Outlook", 66-76 (Oct. 2020). 